\title{
RECONOCIMIENTO Y TUTELA DE DERECHOS HUMANOS. PLURALIDAD Y DIVERSIDAD EN LA SOCIEDAD DEMOGRÁTICA*
}

\author{
RECOGNITION AND PROTECTION OF HUMAN RIGHTS: \\ PLURALITY AND DIVERSITY IN DEMOCRATIC SOCIETY
}

\section{Sergio GARCÍA RAMÍREZ**}

RESUMEN: En este artículo se subraya que el orden público nacional e internacional, sustentado en valores y principios acogidos en ambos planos de la normativa jurídica, entraña la vigencia del principio de igualdad entre todas las personas, que es garantía
ABSTRACT: This article underlines the fact that national and international public order, based on values and principles enshrined in both levels of legal provisions, embodies the principle of equality among all persons, which is a guarantee for individuals and a

* Recibido el 9 de octubre de 2020; aprobado el 18 de enero de 2021.

Originalmente, este artículo constituyó una contribución para la Relatoría General del Congreso de la Academia de Derecho Internacional de Derecho Comparado (2021). Por ello, se analiza la materia tomando en cuenta un cuestionario formulado por los relatores generales del Congreso, Laurence Burgorgue-Larsen y Krzysztof Wojtyczek sobre Diversity and Plurality in the Law: Human Rights/Diversité et Pluralité dans le droit: droits humains. En este trabajo se ofrece un panorama sintético del orden jurídico interamericano sobre los temas vinculados directamente con pluralidad y diversidad, concentrado en el tratamiento "regional" de esta materia, sin examinar los sistemas nacionales particulares. En notas a pie de página se hallan las principales fuentes del panorama. En éstas aparecen documentos de la organización regional de Estados (OEA), tratados y convenciones, decisiones de los órganos internacionales de supervisión y algunas referencias a la doctrina interamericana. Por supuesto, esta relación de fuentes es ejemplificativa. Existen una copiosa jurisprudencia y una creciente doctrina acerca de los temas que aquí menciono, ampliamente examinados en el ya largo itinerario del Sistema Interamericano.

** ORCID: 0000-0002-9164-8464. Investigador en el Instituto de Investigaciones Jurídicas; investigador emérito del Sistema Nacional de Investigadores (México); profesor emérito de la Universidad Nacional Autónoma de México y exjuez y expresidente de la Corte Interamericana de Derechos Humanos. Correo electrónico:sgrïjunam@gmail.com.

Agradezco la colaboración de Irving Rodríguez (asistente de investigación, Sistema Nacional de Investigadores, Consejo Nacional de Ciencia y Tecnología) y Tania González Kazén (analista, Observatorio del Sistema Interamericano, Instituto de Investigaciones Jurídicas, UNAM).

Boletín Mexicano de Derecho Comparado, nueva serie, año LIV, núm. 160, enero-abril de 2021, pp. 191-235. 
Esta revista forma parte del acervo de la Biblioteca Jurídica Virtual del Instituto de Investigaciones Jurídicas de la UNAM

para los individuos y principio rector de la función del Estado. Sin perjuicio de este postulado, es preciso observar las diferencias reales que existen entre los individuos y los grupos en el seno de una misma sociedad nacional, y garantizar el respeto a esa diversidad, en varios ámbitos y con múltiples consecuencias. Esto entraña la existencia y aplicación de otro principio, que complementa al de igualdad: especificidad, que no significa, en modo alguno, discriminación. En la sociedad contemporánea hay múltiples factores de diversidad y pluralidad. De hecho, la sociedad democrática es una sociedad heterogénea, en la que florecen múltiples requerimientos, intereses, convicciones y opiniones. De todo ello deriva un derecho a la diversidad: la posibilidad de "ser diferente" y la consecuente facultad de existir y convivir dentro de la pluralidad social, fijando y alcanzando el destino particular libremente elegido. Asimismo, esta situación es el fundamento de los deberes específicos del Estado para el respeto y la garantía de los derechos individuales. El presente artículo revisa esta materia desde la perspectiva de la jurisprudencia de la Corte Interamericana de Derechos Humanos (Corte IDH). El tribunal regional ha adoptado criterios de gran importancia y trascendencia sobre esta materia, con sustento en buen número de instrumentos interamericanos, invocados en el artículo al que corresponde este resumen. Esos criterios figuran en un amplio conjunto de opiniones consultivas y sentencias emitidos por la Corte IDH. Las vertientes de la pluralidad y la especificidad que aquí se examinan están relacionadas con la situación de grupos (mujeres, indígenas, parejas, familias, por ejemplo) y con el ejercicio de derechos básicos (identidad, convicción, expresión, opción política, también, por ejemplo). Se pasa revista a los deberes del Estado guiding principle of the State's role. Without prejudice to this premise, it is necessary to observe the real differences that exist between individuals and groups within the same national society, and to ensure respect for this diversity, in various spheres and with multiple consequences. This implies the existence and application of another principle, which complements that of equality: specificity, which in no way means discrimination. In contemporary society, there are multiple factors of diversity and plurality. In fact, democratic society is a heterogeneous society in which numerous requirements, interests, convictions, and opinions thrive. This gives rise to a right to diversity arises: the possibility of "being different" and the ensuing right to exist and co-exist within social plurality, establishing and achieving one's own freely chosen destiny. This situation is also the basis for the specific duties of the State to respect and guarantee individual rights. This article examines this issue from the perspective of Inter-American Court of Human Rights (IACHR) case law. The Regional Court has adopted criteria of great importance and transcendence in this matter, based on a good number of inter-American instruments mentioned in the article covered by this review. These criteria are to be found in a wide range of advisory opinions and judgments issued by the IACHR. The aspects of plurality and specificity examined herein are related to the situation of groups (for example, women, indigenous people, couples, and families) and to the exercise of basic rights (for example, identity, conviction, expression, and political opinion). The duties of the guarantor State are discussed, and emphasis is placed on the application of economic, social, cultural,and environmental rights. 
Esta revista forma parte del acervo de la Biblioteca Jurídica Virtual del Instituto de Investigaciones Jurídicas de la UNAM

garante y se pone énfasis en la aplicación de los derechos económicos, sociales, culturales y ambientales.

Palabras clave: orden jurídico interamericano; declaraciones internacionales; convenciones internacionales; pluralidad/ diversidad; Corte IDH; discriminación/ trato diferente; igualdad/especificidad; individuos/grupos; indígenas; convicciones; expresión; parejas/familia; democracia/ derechos políticos; identidad; deberes del Estado.
Keyzords: inter-american legal system; international declarations; international conventions; plurality/diversity; Inter-American Court of Human Rights; discrimination/ different treatment; equality/specificity; individuals/groups indigenous peoples; convictions; expression; couples/family; democracy/political rights; identity; duties of the State.

Sumario: I. Preámbulo: hipótesis y objetivo. II. Marco normativo interamericano: principios y normas. III. Diversidad y pluralidad en la sociedad heterogénea. IV. Discriminación y trato diferente. V. Órdenes jurídicos especiales: indígenas. VI. Libertad de convicciones y expresión. VII. Parejas y familia. VIII. Temas de bioética. IX. Democracia y derechos políticos. X. Tensión entre órdenes normativos. XI. Pro persona y otros principios específicos. XII. Identidad personal. XIII. Estado garante. XIV. Derecho común regional y estatutos especiales. XV. Derechos económicos, sociales, culturales y ambientales. XVI. Estado garante de derechos de integrantes de grupos y sectores. XVII. Bibliografia.

\section{PreÁmbUlo. Hipótesis de tRABAJO}

Los derechos humanos son el dato más universal del orden jurídico, en el sentido de que todas las personas (físicas) son titulares de derechos y libertades que los Estados deben respetar y garantizar. Sin embargo, las condiciones en que actúan y se desarrollan los individuos distan mucho de ser las mismas. Existe, pues, diversidad material (y, eventualmente, jurídica) entre los individuos. Además, éstos pueden asumir diversos objetivos individuales o integrarse (de grado o por el imperio de los hechos) en grupos distintos en el seno de una misma sociedad nacional y universal. Si el orden jurídico no reconoce esta diversidad y estas facultades de orientación propia (con sustento en la autonomía individual), los derechos humanos 
Esta revista forma parte del acervo de la Biblioteca Jurídica Virtual del Instituto de Investigaciones Jurídicas de la UNAM

resultarían ilusorios o estarían sujetos al imperio de órganos de poder o mayorías populares.

De lo anterior deriva la necesidad de preguntar si el orden jurisdiccional interamericano (criterios de la Corte IDH) reconocen y protegen los derechos de quienes ejercen su derecho a la diversidad (ser "diferentes" y respetados como tales), su facultad de existir y convivir dentro de la pluralidad que prevalece en una sociedad, elegir su destino particular y la forma de alcanzarlo. Este trabajo parte de la hipótesis de que la jurisprudencia del tribunal de San José sobre la materia reconoce y tutela los derechos de quienes ejercen su derecho a la diversidad de vida, desarrollo y convicciones. Aquí se aporta una respuesta a esta interrogante, con sustento en el análisis de las decisiones de la Corte IDH sobre diversos extremos en los que se manifiesta el tratamiento de la materia por esa vía jurisdiccional.

\section{MARCO NORMATIVO INTERAMERICANO: PRINCIPIOS Y NORMAS}

Como dije en el preámbulo, el reconocimiento de la diversidad y la pluralidad en una sociedad (mundial, regional o nacional) constituye un dato radical del orden jurídico de los derechos humanos atento a los valores y principios de la democracia, a la que me referiré en sus dimensiones a) formal o representativa, b) participativa, y c) integral o material (sistema de vida), ${ }^{1}$ que aparecen en la normativa interamericana ( $c f r$. Opinión Consultiva OC8/87, 1987, párrafo 26 y San Miguel Sosa y otras vs. Venezuela, 2018, párrafos 117 y 144). Aludiré con frecuencia a la sociedad democrática, constantemente invocada por la jurisprudencia interamericana. La naturaleza y el contenido de ese concepto deben apreciarse a partir de la centralidad reconocida al ser humano, el marco que proveen los derechos y libertades reconocidos por el moderno orden constitucional e internacional, y las ideas más avanzadas en torno al papel de la sociedad y el Estado en la protección de los derechos básicos del ser humano.

En el establecimiento, desarrollo y aplicación de ese orden jurídico ocupa un lugar primordial el principio de igualdad, al que se reconoce

1 Cfr. Amaya Úbeda de Torres (2007); Asdrúbal Aguiar Aranguren (2012); Laurence Burgorgue-Larsen y Amaya Úbeda de Torres (2008, pp. 649-650); Carta Democrática Interamericana ([CDI], 11/09/2001, art. 2); CIDH (2011, párrafo 5); Yatama vs. Nicaragua (2005, párrafos 192-193), y Gelman vs. Uruguay (2011, párrafo 239). 
Esta revista forma parte del acervo de la Biblioteca Jurídica Virtual del Instituto de Investigaciones Jurídicas de la UNAM

jerarquía de ius cogens internacional. ${ }^{2}$ Por supuesto, no pretendo internarme en este concepto. Me atengo a la caracterización que provee la Convención de Viena sobre el Derecho de los Tratados acerca de las normas imperativas (ius cogens) y a la recepción de este asunto en la jurisprudencia de la Corte de San José (supra, III). Considero que en el mismo orden puede figurar - con diversas formulaciones - el principio de especificidad (cfr. Sergio García Ramírez, 2018, p. 182 y 2019, p. 658), complemento de la igualdad. Especificidad implica trato diferente (es decir, "específico") a quienes son también diferentes (de hecho, o en virtud del orden normativo), a fin de rescatarles de la injusticia o la inequidad en la que se podría incurrir si se aplica en forma mecánica e indistinta el criterio de igualdad formal.

Del modo en que se ha considerado que el principio de igualdad y no discriminación forma parte del ius cogens internacional, se puede considerar que la adopción de criterios específicos para atender situaciones también específicas - adopción ampliamente reconocida por el derecho internacional convencional- se inscribe igualmente en el ius $\mathrm{co}^{-}$ gens. Sin embargo, esta consideración no forma parte de las conclusiones del presente trabajo. $\mathrm{Al}$ amparo de la especificidad, que acoge correctivos y modalidades indispensables para establecer el sentido y el alcance de la igualdad, se desenvuelve la tutela de los derechos de quienes forman parte de grupos diversos dentro de la sociedad plural.

En este trabajo me referiré exclusivamente al orden jurídico interamericano, vinculado al Sistema regional de protección de esos derechos y formalmente construido a partir de 1945 (cfr. Unión Panamericana, 1956, pp. 20-24). El Sistema es heterogéneo y se proyecta con intensidad y alcances diversos en el conjunto de Estados que componen "Las Américas". Esta expresión pone de manifiesto la pluralidad material y jurídica que caracteriza a la región: varias Américas (Sergio García Ramírez, 2019, pp. 113 y 114); en cada una, Estados con rasgos propios, y en cada Estado, grupos y sectores con características singulares. Todo esto debe ser consi-

2 Cfr. CIDH (2019, p. 25); Informe 64/11 (2011, párrafo 359); Informe 75/15, (2015, párrafo 144); Opinión Consultiva OC-18/0 (2003, párrafo 101), y Opinión Consultiva OC-24/ 17 (2017, párrafo 61). Sobre el principio de igualdad, $c f r$ r Rodrigo Uprimmy Yepes y Luz María Sánchez Duque (2019, pp. 708 y ss).

Esta obra está bajo una Licencia Creative Commons Atribución-NoComercial-SinDerivar 4.0 Internacional, IIJ-UNAM. Boletín Mexicano de Derecho Comparado, núm. 160, enero-abril de 2021, pp. 191-235. 
Esta revista forma parte del acervo de la Biblioteca Jurídica Virtual del Instituto de Investigaciones Jurídicas de la UNAM

derado al examinar las normas y prácticas sobre diversidad y pluralidad en el ámbito americano.

El derecho interamericano - "duro" y "suave": doble marco para la atención de la diversidad y la pluralidad - se deposita en numerosos instrumentos, cada vez más abundantes y comprensivos, en acuerdos o declaraciones de instancias políticas regionales, y en resoluciones y sentencias de los órganos de supervisión creados en el marco del Sistema. La jurisprudencia regional ha precisado que la norma internacional se compone con dos elementos: texto convencional e interpretación jurisdiccional (cfr. Almonacid Arellano y otros vs. Chile, 2006, párrafo 124, y Gelman vs. Uruguay (2013, párrafo 66).

Aquí aludiré tanto a la Organización de los Estados Americanos, cuya Carta constitutiva data de $1948,{ }^{3}$ como a la Comisión (1959) (c $f r$. Unión Panamericana, 1960, p. 11; Felipe González Morales, 2013, pp. 31 y 32, y Bertha Santoscoy (1995, párrafo 18) y a la Corte (cfr. Corte IDH 2005 y Sergio García Ramírez, 2018b, pp. 23-72) interamericanas de derechos humanos. La organización y la normativa a la que me estoy refiriendo tienen correspondencias en el sistema universal y en otros sistemas regionales. ${ }^{4}$ De ellos ha tomado conceptos y orientaciones el Sistema Interame-

3 En la IX Conferencia Internacional Americana sobre Problemas de la Guerra y de la Paz (1945) los Estados americanos convinieron consolidar el derecho interamericano. Posteriormente, adoptaron la Carta de la Organización de los Estados Americanos en la Novena Conferencia Internacional Americana, en Bogotá, Colombia (1948). (Cfr. Unión Panamericana, 1956, pp. 124-145)

4 En el ámbito universal: Declaración Universal de los Derechos Humanos, Pacto Internacional de Derechos Civiles y Políticos, Pacto Internacional de Derechos Económicos, Sociales y Culturales, Convención Internacional sobre la Eliminación de todas las Formas de Discriminación Racial, Convención sobre la Eliminación de todas las Formas de Discriminación contra la Mujer, Convención sobre los Derechos del Niño, Convención contra la Tortura y otros Tratos o Penas Crueles, Inhumanos o Degradantes, Convención Internacional sobre la protección de los Derechos de todos los Trabajadores Migratorios y de sus Familiares, Convención sobre los Derechos de las Personas con Discapacidad y Convención Internacional para la Protección de todas las Personas contra las Desapariciones Forzadas, así como sus respectivos comités. En el ámbito europeo: Convenio Europeo de Derechos Humanos, que estableció una Comisión — suprimida por el Protocolo 11 de 1999 - y un Tribunal Europeo de Derechos Humanos. En el continente africano, la Unión Africana acogió la Carta Africana sobre los Derechos Humanos y de los Pueblos; además, la Comisión y la Corte Africanas sobre Derechos Humanos y de los Pueblos, establecidas por la Carta Africana y su Protocolo 
Esta revista forma parte del acervo de la Biblioteca Jurídica Virtual del Instituto de Investigaciones Jurídicas de la UNAM

ricano en un proceso de diálogo y fertilización recíproca. Muchas decisiones iniciales de las instancias interamericanas recibieron la influencia de la regulación mundial, así como de la europea. Reconozco esta circunstancia, pero me limito a considerar la tutela de la diversidad y la pluralidad en nuestro ámbito regional.

En la región americana y en los órganos que constituyen su andamiaje institucional figuran entes destinados a la promoción o la defensa de derechos e intereses de grupos y sectores sociales, con alcance continental (por ejemplo, mujeres y niños). ${ }^{5}$ En la Comisión Interamericana operan relatorías que tienen el mismo propósito. ${ }^{6}$

Para los fines de este trabajo, tomaré en cuenta tanto las más relevantes declaraciones regionales (generales: Declaración Americana de Derechos y Deberes del Hombre, de $1948,{ }^{7}$ y especiales: así, en torno a los derechos de pueblos indígenas, ${ }^{8}$ y otros documentos que enuncian principios, reglas y medidas), como los tratados, convenciones y protocolos más significativos y los pronunciamientos emitidos por los órganos del sistema, principalmente las opiniones consultivas (Convención Americana sobre

para la creación de una Corte Africana de los Derechos Humanos y de los Pueblos, respectivamente.

5 Instituto Interamericano del Niño, la Niña y Adolescentes, Comisión Interamericana de Mujeres y Programa Interamericano sobre los Derechos Humanos de la Mujer y la Equidad e Igualdad de Género.

6 La CIDH cuenta con 13 relatorías que brindan atención prioritaria a ciertos grupos, comunidades y pueblos. Entre ellas, las relatorías sobre los derechos de los pueblos indígenas, de las mujeres, de los migrantes, los derechos de la niñez, personas afrodescendientes y contra la discriminación racial, personas LGBTI, personas mayores y personas con discapacidad. http://wrew.oas.org/es/cidh/mandato/relatorias.asp Asimismo, cfr. Felipe González Morales, 2013, pp. 195-204.

7 La Declaración Americana de los Derechos y Deberes del Hombre (DADDH) fue aprobada en 1948 en la IX Conferencia Internacional Americana en Bogotá. Es el primer instrumento relativo al reconocimiento y protección de derechos humanos con alcance supranacional. (Cfr. Unión Panamericana, 1956, pp. 203-209)

8 La Declaración Americana sobre los Derechos de los Pueblos Indígenas fue aprobada el 14 de junio de 2016, en el 46 Periodo Ordinario de Sesiones de la Asamblea General de la Organización de Estados Americanos. El proceso de creación de este instrumento comenzó en 1989, cuando la Asamblea General encargó a la CIDH un primer borrador (cfr. Felipe González Morales, 2013, p. 256, y Fergus Mackay, pp. 159 y ss.). La Declaración reconoce los derechos humanos de mujeres, hombres, niños, niñas y adolescentes indígenas. Sus disposiciones protegen la diversidad, la identidad cultural y el desarrollo. https:// wrere.oas.org/es/sadye/documentos/res-2888-16-es.pdf

Esta obra está bajo una Licencia Creative Commons Atribución-NoComercial-SinDerivar 4.0 Internacional, IIJ-UNAM. Boletín Mexicano de Derecho Comparado, núm. 160, enero-abril de 2021, pp. 191-235. 
Esta revista forma parte del acervo de la Biblioteca Jurídica Virtual del Instituto de Investigaciones Jurídicas de la UNAM

Derechos Humanos [CADH], 1969, art. 64), las sentencias (CADH, arts. 61-63) y otras resoluciones del tribunal regional y varias declaraciones, recomendaciones y principios de la Comisión Interamericana $(\mathrm{CADH}$, art. 41).

La Declaración Americana de 1948 y la CADH de 1969 proclaman la universalidad de los derechos reconocidos en ellas y rechazan la discriminación en su ejercicio (DADDH, art. II, y CADH, art. 1o.). En consecuencia, favorecen el reconocimiento de la diversidad y la pluralidad entre los individuos - con doble fuente: origen y elección - y, por ende, entre los grupos y sectores en los que aquéllos aparecen, desarrollan su existencia y procuran su destino. A este respecto, retengamos el propósito enunciado por los autores de la Convención: "consolidar en este Continente, dentro del cuadro de las instituciones democráticas, un régimen de libertad personal y de justicia social, fundado en el respeto de los derechos esenciales del hombre" (CADH, preámbulo). Entre éstos se halla el derecho de elegir y ejercer sus facultades en los distintos planos a los que se refiere este trabajo.

\section{DIVERSIDAD Y PLURALIDAD \\ EN LA SOCIEDAD HETEROGÉNEA}

Los textos interamericanos recogen la diversidad y pluralidad que caracterizan a la sociedad de esta región, y sustentan la decisión política y jurídica de amparar a los individuos en el ejercicio tanto de los derechos comunes como de los derechos específicos inherentes a esas diversidades y pluralidades. El mismo espíritu anima a la Carta Democrática Interamericana (CDI). De ahí - por ejemplo - el reconocimiento que esta fórmula sobre el "régimen plural de partidos y organizaciones políticas" (CDI, art. 3o.) como componente fundamental del ejercicio de la democracia.

En los países de "las Américas" concurren comunidades o sectores diferentes, con características acentuadas que reclaman tratamiento específico. Los instrumentos del sistema - fundacionales o posteriores - contienen expresiones que acreditan esta orientación tutelar. En el mismo sentido opera el concepto de sociedad democrática, al que antes me referí, mencionado en la normativa y en los pronunciamientos de los órganos del Sistema, tanto cuando aluden a la fuente de los derechos y de los co- 
Esta revista forma parte del acervo de la Biblioteca Jurídica Virtual del Instituto de Investigaciones Jurídicas de la UNAM

rrespondientes deberes de los Estados, como cuando se pronuncian sobre las limitaciones o restricciones de aquéllos. ${ }^{9}$

Antes de revisar algunas cuestiones específicas relacionadas con la materia de este trabajo, conviene destacar la amplia legitimación que la normativa interamericana concede para plantear la violación a un derecho. ${ }^{10}$ No se exige que el solicitante, cuya gestión abre la vía internacional, sea víctima de la violación alegada. Esa legitimación abarca a "cualquier persona o grupo de personas, o entidad no gubernamental legalmente reconocida en uno o más Estados miembros de la Organización" (OEA). Con ello se abre la puerta a planteamientos de grupos que pudieran ostentar intereses, derechos o pretensiones diferentes de los correspondientes a la mayoría de la población. El planteamiento puede desembocar en una decisión que reconozca derechos de los integrantes del grupo y que, por lo tanto, asegure el respeto y garantice la pluralidad. ${ }^{11}$

Los Estados Americanos presentan diversas formas de organización política, entre ellas la federal. ${ }^{12}$ Ésta (y sus equivalentes en la división por regiones) implica diversidades sociales y políticas que es preciso atender. Empero, la protección de los derechos humanos trasciende esas diversidades. En la CADH figura la llamada "cláusula federal"13 (art. 28)

9 Cfr. CIDH (2009, párrafos 67-73; Informe 75/15, caso 12.923, Fondo, Rocío San Miguel Sosa y otras, 2015, párrafo 136; Herrera Ulloa vs. Costa Rica, 2004, párrafo 120; Claude Reyes y otros vs. Chile, 2006, párrafos 88-92, y San Miguel Sosa y otra, 2018, párrafos 117 y 144, y Amaya Úbeda de Torres, Democracia y derechos humanos en Europa y América, Madrid, Reus, 2007, pp. 579 y ss.

10 "Cualquier persona o grupo de personas, o entidad no gubernamental legalmente reconocida en uno o más Estados miembros de la Organización, puede presentar a la Comisión peticiones que contengan denuncias o quejas de violación de esta Convención por un Estado parte" (CADH, art. 44). En el mismo sentido, "Convención de Bélem do Pará" (art. 12), y Convención Interamericana sobre la Protección de los Derechos Humanos de las Personas Mayores (art. 36).

11 Cfr. Héctor Faúndez Ledesma (2004, pp. 252-257); Osvaldo Alfredo Gozaíni (2016, pp. 52 y ss); CIDH, Informe 32/05, Petición 642/2003 (2005); Informe 98/09, Petición 4355-02 (2009), y Pueblos Kaliña y Lokono vs. Surinam (2015, párrafos 2 y puntos resolutivos 1-3). Alcalá-Zamora criticó la referencia a "grupos" de individuos, porque constituye una denominación imprecisa. (Cfr. Niceto Alcalá-Zamora, 1974, p. 330).

12 Tienen estructura federal: Argentina, Brasil, Canadá, Estados Unidos, México y Venezuela.

13 "Cuando se trate de un Estado parte constituido como Estado federal, el gobierno nacional de dicho Estado parte cumplirá todas las disposiciones de la presente Convención 
Esta revista forma parte del acervo de la Biblioteca Jurídica Virtual del Instituto de Investigaciones Jurídicas de la UNAM

que responde a este sentido tutelar. El Estado no puede invocar su organización federal para omitir el cumplimiento de las obligaciones derivadas de la normativa internacional. ${ }^{14}$

\section{DISCRIMINACIÓN Y TRATO DIFERENTE}

El principio de igualdad, invocado por la Corte IDH como norma de jus cogens internacional, se asocia a la proscripción de cualquier forma de discriminación. Los textos interamericanos mencionan algunas variantes de ésta (raza, color, sexo, idioma, religión, opiniones políticas o de otro orden, origen nacional o social, posición económica, nacimiento o cualquier otra condición social). ${ }^{15}$

$\mathrm{Al}$ analizar el concepto de discriminación, la jurisprudencia interamericana destaca la legitimidad de las diferencias de trato a personas o grupos, justificada por la diversidad de condiciones en las que éstos se encuentran. ${ }^{16}$ Así queda a salvo la tutela diferenciada de personas cuya situación de hecho justifica esa tutela (Roberto Berizonce, 2009, pp. 97 y ss.). Esa protección diferenciada opera tanto en el examen de la diversidad y la pluralidad, como en la atención a los grupos vulnerables y sus integrantes.

Como desarrollo de las normas regionales que implican una profunda relectura de los principios tutelares inherentes a la diversidad y la pluralidad, cabe mencionar algunos instrumentos emitidos para combatir formas genéricas o específicas de discriminación o manifestaciones de violencia que reduce o desconoce derechos de amplios sectores de la sociedad. Estos documentos, que mencionaremos en el presente trabajo, figuran

relacionadas con las materias sobre las que ejerce jurisdicción legislativa y judicial".

14 Cfr. Garrido Baigorria vs. Argentina (1998, párrafo 46); Escher y otros vs. Brasil (2009, párrafo 219), y Garibaldi vs. Brasil (2009, párrafo 146).

15 Cfr. CADH (art. 1); Protocolo Adicional a la Convención Americana sobre Derechos Humanos en materia de Derechos Económicos, Sociales y Culturales "Protocolo de San Salvador" (art. 3); Convención Interamericana contra el Racismo, la Discriminación Racial y Formas Conexas de Intolerancia (art. 1); Convención Interamericana contra Toda Forma de Discriminación e Intolerancia (art. 1).

16 Cfr. CIDH, Informe 04/01, Caso 11.625 (2001, párrafo 31); CIDH, Compendio sobre la igualdad y no discriminación. Estándares Interamericanos, op. cit., párrafo 36; OC-4/84 (1984, párrafos 55-57), y OC-18/03 (2003, párrafo 89). 
Esta revista forma parte del acervo de la Biblioteca Jurídica Virtual del Instituto de Investigaciones Jurídicas de la UNAM

en el orden regulador característico de nuestra región. Disponen y detallan medidas de diverso carácter - no sólo legislativas - en relación con grupos y sectores de la sociedad. Queda de manifiesto la pluralidad de ésta y el propósito de brindar tutela específica a tales grupos y sectores.

Un ejemplo destacado sobre un sector social de suma importancia es la tutela de derechos específicos de las mujeres prevista en la Convención de Belém do Pará, ${ }^{17}$ destinada a enfrentar la violencia. ${ }^{18}$ Su predecesora mundial, la CEDAW, ${ }^{19}$ se concentró en puntos de discriminación, ${ }^{20}$ muchos de los cuales entrañan violencia. Belém do Pará obedece al objetivo - procurado frente a escollos y resistencias de diversa naturalezade avanzar en el reconocimiento y la protección de los derechos de las mujeres, y ha informado cambios en la normativa de los Estados de la región (Luz Patricia Mejía, 2012, pp. 196-197 y Comisión Interamericana de Mujeres, 2001, p. 91). Esta convención, aplicada por la Corte IDH con designio transformador (Sergio García Ramírez, pp. 11 y ss. Y Esther Vicente, 2010, pp. 149 y ss.), ocupa un lugar eminente en la jurisprudencia

17 La Convención Interamericana para Prevenir, Sancionar y Erradicar la Violencia contra la Mujer ("Convención de Belém do Para") fue adoptada en Belém do Para, Brasil, en 1994. Dispone obligaciones de cumplimiento inmediato y deberes de carácter progresivo. Establece el derecho de las mujeres a una vida libre de violencia; ésta constituye una ofensa a la dignidad humana. https://wrew.oas.org/juridico/spanish/tratados/a-61.html. Asimismo, cfr. Felipe González Morales (2013, p. 241).

18 Se denomina "violencia" a "cualquier acción o conducta, basada en su género, que cause muerte, daño o sufrimiento físico, sexual o psicológico a la mujer, tanto en el ámbito público como en el privado". "Convención de Belém do Para" (art. 1).

19 La Convención sobre la Eliminación de Todas las Formas de Discriminación contra la Mujer (CEDAW) fue adoptada el 18 de diciembre de 1979. Es el segundo instrumento internacional más ratificado por los Estados miembros de la ONU, después de la Convención sobre los Derechos del Niño. Se orienta a proteger y promover la igualdad de género y la creación de políticas e instituciones con perspectiva de género con el fin de erradicar los estereotipos, prejuicios y discriminación hacia las mujeres.

20 “ $[\mathrm{L}]$ a expresión 'discriminación contra la mujer’ denotará toda distinción, exclusión o restricción basada en el sexo que tenga por objeto o resultado menoscabar o anular el reconocimiento, goce o ejercicio por la mujer, independientemente de su estado civil, sobre la base de la igualdad del hombre y la mujer, de los derechos humanos y las libertades fundamentales en las esferas política, económica, social, cultural y civil o en cualquier otra esfera". CEDAW (art. 1). 
Esta revista forma parte del acervo de la Biblioteca Jurídica Virtual del Instituto de Investigaciones Jurídicas de la UNAM

interamericana, principalmente a través de la incorporación de perspectiva de género, criterio rector con gran fuerza expansiva. ${ }^{21}$

Otra convención que reconoce derechos de numerosos grupos y ordena la adopción de medidas que concurran a protegerlos es la relativa a quienes padecen restricciones derivadas de alguna forma de discapacidad. ${ }^{22}$ Se ordena a los Estados poner en práctica medidas conducentes al efectivo ejercicio de libertades y derechos (art. III), cuya práctica tropieza con múltiples obstáculos.

En la misma línea figura la Convención sobre adultos mayores, condición etaria - antípoda de la niñez - en la que se encuentra un apreciable número de personas con creciente presencia en la población americana. ${ }^{23}$ Esa convención, al igual que las mencionadas anteriormente, alienta medidas normativas y sociales de amplio espectro. ${ }^{24}$

21 En el caso González y otras ("Campo Algodonero"), la Corte señala que la capacitación con perspectiva de género: “...implica no sólo un aprendizaje de las normas, sino el desarrollo de capacidades para reconocer la discriminación que sufren las mujeres en su vida cotidiana. En particular, las capacitaciones deben generar que todos los funcionarios reconozcan las afectaciones que generan en las mujeres las ideas y valoraciones estereotipadas en lo que respecta al alcance y contenido de los derechos humanos". (2009, párrafo 540). Se ha implementado la perspectiva de género en varios casos en que se analiza la violencia contra las mujeres, por ejemplo: Penal Miguel Castro Castro vs. Perú (2006, párrafo 5); Rosendo Cantú y otra vs. México (2010, párrafos 108, 177, 182, 246, punto resolutivo 17); Velásquez Paiz y otros vs. Guatemala (2015, párrafos 229-269, puntos resolutivos 3 y 4); Mujeres Víctimas de Tortura Sexual en Atenco (2018, párrafos 338-365, puntos resolutivos 3 y 6), y Fernández Ortega vs. México (2010, párrafos 118, 131, 193, 196, 197 y 198).

22 La Convención Interamericana para la Eliminación de Todas las Formas de Discriminación contra las Personas con Discapacidad fue adoptada en la Ciudad de Guatemala el 6 de julio de 1999. Reafirma los derechos humanos de quienes presentan alguna forma de discapacidad, en un marco de dignidad e igualdad. Reconoce la validez de aplicar acciones afirmativas para promover la integración y desarrollo de las personas con discapacidad. Cfr. Felipe González Morales (2013, p. 248). La Convención se encuentra disponible en: https://wrere.oas.org/juridico/spanish/tratados/a-65.html

23 En 2018, 8.87\% de la población mundial tenía 65 años o más. En América Latina y el Caribe y Norteamérica la proporción es de 8 y 16\%, respectivamente. Cfr. http://wdi. worldbank.org/table/2.1\#

24 Entre los derechos que reconoce la Convención Americana sobre la Protección de los Derechos Humanos de las Personas Mayores, se encuentran los relativos a igualdad y no discriminación por razones de edad (art. 5), autonomía e independencia (art. 7), libertad de expresión (art. 14), seguridad social para garantizar una vida digna (art. 17), recreación (art. 22) e identidad cultural (art. 21).

Esta obra está bajo una Licencia Creative Commons

Atribución-NoComercial-SinDerivar 4.0 Internacional, IIJ-UNAM.

Boletín Mexicano de Derecho Comparado, núm. 160, enero-abril de 2021, pp. 191-235. 
Esta revista forma parte del acervo de la Biblioteca Jurídica Virtual del Instituto de Investigaciones Jurídicas de la UNAM

Los instrumentos de más reciente ingreso en el derecho convencional americano, recientemente suscritos en Antigua, Guatemala, reconocen la existencia y los derechos de diversos grupos y sectores y combaten cualesquiera formas de discriminación, ${ }^{25}$ entre ellas, acentuadamente, la que obedece a motivos étnicos. ${ }^{26} \mathrm{La}$ adopción de esta normativa internacional ha marchado lentamente. ${ }^{27}$

Agreguemos los lineamientos promovidos por la Cumbre Judicial Iberoamericana ${ }^{28}$ para garantizar el acceso a la justicia de individuos que se hallan en situación de vulnerabilidad (Reglas de Brasilia ${ }^{29}$ y Protocolo de Santiago), ${ }^{30}$ situación característica de los desiguales, los diferen-

25 La Convención Interamericana contra Toda Forma de Discriminación e Intolerancia fue adoptada en La Antigua, Guatemala el 5 de junio de 2013. Protege el principio de igualdad y no discriminación e intolerancia con respecto a diversos grupos de la sociedad, como migrantes, refugiados, desplazados, grupos religiosos, personas con discapacidad, condición social, etcétera. Doce Estados formaron esta Convención (Argentina, Bolivia, Brasil, Chile, Colombia, Costa Rica, Ecuador, Haití, México, Panamá, Perú, Uruguay). Hasta 2020 sólo dos (México y Uruguay) la han ratificado. Convención. http://wrere.oas. org/es/sla/ddi/tratados_multilaterales_interamericanos_A69_discriminacion_intolerancia.asp

26 La Convención Interamericana contra el Racismo, la Discriminación Racial y Formas Conexas de Intolerancia fue adoptada en La Antigua, Guatemala, el 5 de junio de 2013. Protege el principio de igualdad y dispone medidas y derechos en favor de las personas que sufren discriminación racial, con el fin de salvaguardar su dignidad en una sociedad pluralista y democrática.

27 Doce Estados suscribieron este instrumento (Argentina, Bolivia, Brasil, Chile, Colombia, Costa Rica, Ecuador, Haití, México, Panamá, Perú, Uruguay). Sólo cuatro (México, Ecuador, Antigua y Barbuda, Costa Rica y Uruguay) la han ratificado. http://wrere.oas. org/es/sla/ddi/tratados_multilaterales_interamericanos_A-68_racismo.asp

28 La Cumbre Judicial Iberoamericana es "una estructura de cooperación, concertación e intercambio de experiencias, que se articula a través de las máximas instancias de los Poderes Judiciales de la región Iberoamericana”. Se integra por las judicaturas de Andorra, Argentina, Bolivia, Brasil, Chile, Colombia, Costa Rica, Cuba, Ecuador, El Salvador, España, Guatemala, Honduras, México, Nicaragua, Panamá, Paraguay, Perú, Portugal, Puerto Rico, República Dominicana, Uruguay y Venezuela. http://wrere.cumbrejudicial. org/institucional/quienes-somos

29 Reglas de Brasilia sobre Acceso a la Justicia de las Personas en Condición de Vulnerabilidad, XIV Cumbre Judicial Iberoamericana, Brasilia, 2008. https://wwreacnur.org/ fileadmin/Documentos/BDL/2009/7037.pdf

30 Protocolo iberoamericano de actuación judicial para mejorar el acceso a la justicia de personas con discapacidad, migrantes, niñas, niños, adolescentes, comunidades y pueblos indígenas, XVII Cumbre Judicial Iberoamericana, Santiago, 2014. http://wrere.cum- 
Esta revista forma parte del acervo de la Biblioteca Jurídica Virtual del Instituto de Investigaciones Jurídicas de la UNAM

tes, los distintos, los ajenos: ${ }^{31}$ es decir, el vasto ejército de quienes invocan el respeto y la garantía de la diversidad, derivada de múltiples factores.

En la revisión del estado que guarda el derecho interamericano de los derechos humanos es necesario tomar en cuenta el importante progreso que implican estos últimos documentos, impulsados por el diálogo jurisdiccional de los lustros recientes, que supera el tradicional aislamiento o reticencia de los órganos judiciales. La Cumbre Judicial Iberoamericana favorece la atención especial de los derechos de ciertos sectores que en América son mayoritarios, en su conjunto- y propicia una suerte de "Derecho judicial codificado" (Sergio García Ramírez, 2016a, p. 85), expresión que utilizo para fines expositivos. De este naciente marco normativo se benefician la pluralidad y la diversidad, tanto como la tutela de los grupos vulnerables.

\section{V. ÓRDENES JURÍDICOS ESPECIALES: INDÍGENAS}

Numerosas decisiones de la Comisión y de la Corte han inspirado o recogido la normativa dispuesta o propuesta por los instrumentos, tratados y protocolos que se mencionan en este panorama. Por otra parte, también cabe señalar un proceso inverso: la generación, por vía jurisdiccional, de criterios que constituyen el fundamento de ciertos tratados (así, en materia de desaparición forzada). ${ }^{32}$

brejudicial.org/productos-y-resultados/productos-axiologicos/item/38-protocolo-de-acceso-a-la-justiciapara-personas-y-grupos-vulnerables

31 “(S)e consideran en condición de vulnerabilidad aquellas personas que, por razón de su edad, género, estado físico o mental, o por circunstancias sociales, económicas, étnicas y/o culturales, encuentran especiales dificultades para ejercitar con plenitud ante el sistema de justicia los derechos reconocidos por el ordenamiento jurídico. Podrán constituir causas de vulnerabilidad, entre otras, las siguientes: la edad, la discapacidad, la pertenencia a comunidades indígenas o a minorías, la victimización, la migración y el desplazamiento interno, la pobreza, el género y la privación de libertad". Reglas de Brasilia, sección 2a. Beneficiarios de las Reglas.

32 En sus primeros casos contenciosos, la Corte estableció la caracterización de la desaparición forzada de personas, retomada por la Convención Interamericana sobre Desaparición Forzada de Personas. Cffr. Velásquez Rodríguez vs. Honduras (1988, párrafos 155-158), y Godínez Cruz vs. Honduras (1989, párrafos 163-167).

Esta obra está bajo una Licencia Creative Commons

Atribución-NoComercial-SinDerivar 4.0 Internacional, IIJ-UNAM.

Boletin Mexicano de Derecho Comparado, núm. 160, enero-abril de 2021, pp. 191-235. 
Esta revista forma parte del acervo de la Biblioteca Jurídica Virtual del Instituto de Investigaciones Jurídicas de la UNAM

También debemos citar la admisión de los órdenes jurídicos especiales que existen y subsisten en varios países de la región. Destacan tanto la Declaración Americana sobre los Derechos de los Pueblos Indígenas - vinculada con la previa Declaración de Naciones Unidas - ${ }^{33}$ como el fuerte reconocimiento jurisprudencial del régimen jurídico establecido por medio de los usos y las costumbres de esos pueblos. ${ }^{34}$ Este reconocimiento alcanza a la normativa nacional y a la jurisprudencia de varios países de la región. $^{35}$

La jurisprudencia interamericana ha conocido violaciones sistemáticas de derechos de los miembros de comunidades indígenas, tema que suscitó el análisis de la titularidad de derechos humanos por personas colectivas, no sólo individuales. ${ }^{36}$ Frente al amplio número de graves violaciones, que implicaban el desconocimiento de derechos ancestrales, la Corte IDH rescató el respeto y la vigencia del orden consuetudinario y desarrolló una nueva lectura sobre el derecho de los indígenas y sus comunidades a disponer de sus bienes, al amparo de la CADH y bajo parámetros distintos de los generalmente aplicables al derecho de propiedad. ${ }^{37}$

33 Declaración de las Naciones Unidas sobre los Derechos de los Pueblos Indígenas, 13 de septiembre de 2007. https://wrere.un.org/development/desa/indigenous-peoples-es/declaracionsobre-los-derechos-de-los-pueblos-indigenas.html

34 Cfr. CIDH, OEA/Ser.L/V/II (2015, párrafo 102); OAS/Ser.L/V/II (2019, párrafo 242); Comunidad Mayagna (Sumo) Awas Tingni vs. Nicaragua (2001, párrafos 138 y 151); Comunidad Indígena Sawhoyamaxa vs. Paraguay (2006, párrafo 83); Pueblo Saramaka vs. Surinam (2007, párrafo 178); Tiu Tojín vs. Guatemala (2008, párrafo 96); Pueblo Indígena Kichwa de Sarayaku vs. Ecuador (2012, párrafo 264); Pueblos Indígenas Kuna de Madungandí y Emberá de Bayano y sus Miembros vs. Panamá (2014, párrafo 167); Pueblos Kaliña y Lokono vs. Surinam (2015, párrafos 159 y 283), y Pueblo Indígena Xucuru y sus miembros vs. Brasil (2018, párrafo 131).

35 Cfr. Barie Cletus Gregor (2003, pp. 87 y ss.). Por lo que hace a México, cfr. Constitución Política de los Estados Unidos Mexicanos (art. 2, inciso A, fracción II); Tribunal Electoral del Poder Judicial de la Federación, Expediente SUP-JDG-9167/2011 (2011, pp. 133 y 134), y Suprema Corte de Justicia de la Nación, Primera Sala, Amparo directo 6/2018.

36 Cfr. Comunidad Mayagna (Sumo) Awas Tingni vs. Nicaragua (2001, párrafos 147-155); Pueblos Kaliña y Lokono vs. Surinam (2015, párrafo 129), y Pueblo Indígena Xucuru y sus miembros vs. Brasil (2018, párrafo 115). Sobre la jurisprudencia interamericana en este tema, cfr. Oswaldo Ruiz Chiriboga y Gina Donoso (2019, pp. 1131 y ss.).

37 En la sentencia del caso Mayagna (Sumo) Awas Tingni la Corte Interamericana determinó que al amparo del artículo 21 de la $\mathrm{CADH}$ se encuentran protegidos los derechos territoriales de los pueblos indígenas. El Tribunal ha mantenido el mismo criterio hasta el caso de Pueblo Indígena Xucuru y sus miembros. Cfr. Maygna (Sumo) Awas Tingni vs. Nicara- 
Esta revista forma parte del acervo de la Biblioteca Jurídica Virtual del Instituto de Investigaciones Jurídicas de la UNAM

La consideración de esta materia ha significado un paso adelante en la recepción de la diversidad y la inserción formal de sistemas jurídicos especiales dentro del sistema regulatorio nacional. Otra vía para asegurar el dominio indígena sobre los bienes de la comunidad - o los que ésta requiere para su sustento - radica en el régimen de consulta a los pueblos acerca del aprovechamiento y destino de esos bienes. ${ }^{38}$

La regulación interamericana pretende la preservación de la cultura indígena, que constituye uno de los datos culturales más relevantes en el conjunto indoamericano y figura en el marco de los derechos económicos, sociales y culturales. ${ }^{39}$ Han menudeado las agresiones a la cultura de las comunidades indígenas, e incluso los hechos tendientes a suprimir la transmisión de ésta en el enlace intergeneracional. ${ }^{40}$

Frente a situaciones de ese carácter, la Corte IDH ha ordenado a los Estados adoptar medidas de protección de la cultura indígena. Estas se asocian, entre otros extremos, con el derecho de los niños ${ }^{41}$ al desarrollo en el espacio (material y cultural) de su comunidad y con la supervivencia también material y cultural de las comunidades. Figuran aquí las disposiciones sobre localización y entrega de restos humanos para la práctica

gua (2001, párrafo 148), y Pueblo Indígena Xucuru y sus miembros vs. Brasil (2018, párrafo 116). Cfr. Karla I. Quintana Osuna (2017, pp. 16-24).

38 Cfr. Declaración Americana sobre los Derechos de los Pueblos Indígenas (arts. XXIII, XXVIII inciso 3 y XXIX inciso 4); CIDH, OEA/Ser.L/V/II, Doc. 34 (2007, párrafos 246, 248 y 297); OEA/Ser.L/V/II, Doc. 47/15 (2015, párrafos 172-224); Informe de Fondo 40/04, Caso 12.053, (2004, párrafo 5); Pueblo Saramaka vs. Surinam (2007, párrafos 127 y 128), y Pueblo Indígena Kichwa de Sarayaku vs. Ecuador (2012, párrafos 159-167). Sobre este tema, $c f r$. Rodolfo Stavenhagen (2007, pp. 47 y ss.).

39 Cfr. Protocolo adicional a la Convención Americana sobre Derechos Humanos en materia de Derechos Económicos, Sociales y Culturales "Protocolo de San Salvador", 17 de noviembre de 1988, artículo 14. A este respecto, $c f r$. Laurence Burgorgue-Larsen y Amaya Úbeda de Torres (2009, pp. 660-662).

40 Es necesario proteger la herencia cultural de los pueblos indígenas, su territorio, naturaleza y conocimientos para las generaciones actuales y futuras. A esto se conoce también como "solidaridad intergeneracional". Cfr. Declaración Americana sobre los Derechos de los Pueblos Indígenas (art. XIII, inciso 1); CIDH (2019, párrafo 49). La Corte IDH ha analizado masacres de pueblos indígenas (Masacres de río negro, Masacre Plan de Sánchez) que han dañado la transmisión de su cultura entre generaciones.

41 Cfr. CIDH, OEA/Ser.L/V/II (2009. párrafo 205); OEA/Ser.L/V/II. Doc. 47/15 (2015, párrafos 323-325); Comunidad Indígena Takye Axa vs. Paraguay (2005, párrafo 172); Chitay Nech y otros vs. Guatemala (2010, párrafo 169); Comunidad Indígena Xákmok Kásek vs. Paraguay (2010, párrafos 261-264), y Masacres de Río Negro vs. Guatemala (2012, párrafo 143-144). 
Esta revista forma parte del acervo de la Biblioteca Jurídica Virtual del Instituto de Investigaciones Jurídicas de la UNAM

de honras fúnebres y el proceso de duelo en las comunidades a las que pertenecieron los fallecidos y pertenecen sus allegados, honras y duelo que revisten características especiales. ${ }^{42}$

\section{LIBERTAD DE CONVICGIONES Y EXPRESIÓN}

En la normativa regional hay pronunciamientos que aseguran la libertad de creencia religiosa, inscrita en la "piedra maestra" de los derechos humanos (cfr. Luigi Ferrajoli, 1995). Esta materia ha figurado, con acento y rasgos específicos, en hipótesis de diversa naturaleza: por ejemplo, casos concernientes a la libertad de expresión, a la relación de los pueblos indígenas con sus territorios ancestrales y a los derechos reproductivos, cuestiones que abordo en otros puntos de este artículo. El respeto a las diversas creencias posee gran importancia y actualidad, tomando en cuenta la creciente diversidad de profesiones religiosas en nuestra región.

Por lo que toca a la libre expresión, en sus vertientes individual y social, ${ }^{43}$ derecho que excluye mecanismos de censura previa, la jurisprudencia interamericana se pronunció por la más amplia libertad con respecto a una obra cinematográfica ${ }^{44}$ - inspirada en una literaria - que planteaba aspectos de la vida de Cristo que no coincidían con las creencias

42 Cfr. Masacre Plan de Sánchez vs. Guatemala, Reparaciones (2004, párrafo 85), en esta sentencia son relevantes las declaraciones de Benjamín Manuel Jerónimo, Eulalio Grave Ramírez y Juan Manuel Jerónimo (víctimas) y los dictámenes de Augusto Willemsen-Díaz y Nieves Gómez Dupuis; Comunidad Moiwana vs. Surinam (2005, párrafos 98, 100 y 103), y Masacres de Río negro vs. Guatemala (2012, párrafos 154, 155, 156, 160, 164 y 165).

43 Cfr. OC-5/85 (1985, párrafo 30); "La última tentación de Cristo" (Olmedo Bustos y otros) vs. Chile (2001, párrafos 64-67); Ivcher Bronstein vs. Perú (2001, párrafos 146-149) y punto resolutivo 5; Mémoli us. Argentina (2013, párrafo 119), y Granier y otros (Radio Caracas Televisión) vs. Venezuela, (2015, párrafo 136). Igualmente, véase Sergio García Ramírez, Alejandra Gonza y Eréndira Nohemí Ramos Vázquez (2019, pp. 39-40), y Laurence BurgorgueLarsen y Amaya Úbeda de Torres (pp. 574-576).

44 Cfr. "La Última Tentación de Cristo" (Olmedo Bustos y otros) vs. Chile (2001, párrafos 70-73). La película censurada fue una adaptación de la novela "La última tentación de Cristo", del escritor griego Nikos Kazantzakis. La modificación corresponde al artículo único, letra a) de la ley de Reforma Constitucional 19.742, mediante la cual se reforma el artículo 19 de la Constitución Política de la República de Chile y que "elimina la censura cinematográfica sustituyéndola por un sistema de calificación y que consagra el derecho a la libre creación artística". https://wrere.leychile.cl/Navegar?idNorma=188827

Esta obra está bajo una Licencia Creative Commons Atribución-NoComercial-SinDerivar 4.0 Internacional, IIJ-UNAM. Boletín Mexicano de Derecho Comparado, núm. 160, enero-abril de 2021, pp. 191-235. 
Esta revista forma parte del acervo de la Biblioteca Jurídica Virtual del Instituto de Investigaciones Jurídicas de la UNAM

mayoritarias de la población. Ese pronunciamiento determinó una reforma constitucional para adecuar la ley suprema interna a la normativa interamericana. Asimismo, la Corte se ha manifestado en favor de la libertad de expresión en el ámbito del debate político, en el que naturalmente se hallan en juego - y deben ser protegidas - las diversas corrientes de pensamiento, características de una sociedad plural. ${ }^{45}$

El tribunal interamericano apreció el nexo entre religión y otros derechos a propósito de las reivindicaciones territoriales de pueblos indígenas. Observó el carácter religioso - espiritual - de la relación entre los pueblos y el ámbito físico en el que han desarrollado su vida, desde tiempos remotos. Esta relación, analizada y respetada por la jurisprudencia, constituye un rasgo diferencial entre el orden jurídico general y el correspondiente a un sector de la población, punto de cruce entre la generalidad y la diversidad. ${ }^{46}$ La cuestión religiosa — vinculada con consideraciones éticas - también quedó a la vista en el examen sobre el acceso a la fecundación asistida, ${ }^{47}$ que atrajo consideraciones científicas y preocupaciones éticas en el complejo espacio de la bioética y el ejercicio de los derechos humanos. Aquí se planteó el derecho a la protección de la vida ${ }^{48}$ (infra, VIII), sujeto a interpretaciones diversas al amparo del relativismo acogido en el primer párrafo del artículo 4o. de la CADH. ${ }^{49}$

En este punto no hubo pronunciamiento directo acerca de la libertad religiosa o la atención a las creencias generales o sectoriales en el ejercicio de ese derecho, pero fue evidente que en la consideración de este asunto figuraba un ingrediente religioso al lado del dato moral. El pronuncia-

45 Cfr. Ricardo Canese vs. Paraguay (2004, párrafos 176-179) y López Lone y otros vs. Honduras (2015, párrafos 162-163).

46 Cfr. CIDH, OEA/Ser.L/V/II (2009, párrafo 150-151); Comunidad Mayagna (Sumo) Awas Tingni vs. Nicaragua (2001, párrafo 149); Comunidad indígena Takye Axa vs. Paraguay (2005, párrafos 131 y 135); Comunidad Indígena Sawhoyamaxa vs. Paraguay (2006, párrafo 118); Pueblo Saramaka vs. Surinam (2007, párrafos 82 y 90), y Kaliña y Lokono..., cit., párrafo 130.

47 Cfr. Artavia Murillo y otros ("Fecundación in vitro") vs. Costa Rica (2012, párrafo 185).

48 Ibidem, párrafos 189 y 264.

49 Cfr. Conferencia Especializada Interamericana sobre Derechos Humanos, San José, Costa Rica, 7-22 de noviembre de 1969, Actas y Documentos, pp. 125 y 159-160; CIDH, Resolución 23/81, Caso 2141, Estados Unidos de América (1981, párrafos 20-31), y Declaración Interpretativa de México. http://wwre.oas.org/es/cidh/mandato/Basicos/convratif.asp. Para una crítica sobre la decisión de la Corte IDH en el caso Artavia Murillo, $c f r$. Francisco Vázquez Gómez-Bisogno (2018, pp. 531-537).

Esta obra está bajo una Licencia Creative Commons

Atribución-NoComercial-SinDerivar 4.0 Internacional, IIJ-UNAM.

Boletín Mexicano de Derecho Comparado, núm. 160, enero-abril de 2021, pp. 191-235. 
Esta revista forma parte del acervo de la Biblioteca Jurídica Virtual del Instituto de Investigaciones Jurídicas de la UNAM

miento de la Corte IDH se produjo en favor de los valores de la sociedad laica y de la libertad en el ámbito de las convicciones morales. (Cfr. Artavia Murillo y otros vs. Costa Rica, 2012, párrafo 185-190)

Las convicciones éticas constituyen un punto de encuentro, diferencia y eventual conflicto entre sectores de la sociedad o entre ésta y los individuos que difieren de los conceptos prevalecientes. Traen consigo una oportunidad de contienda entre las convicciones de la generalidad, que pretende prevalencia o exclusividad, y las de individuos o grupos que reclaman su derecho a la diversidad e impugnan disposiciones que pudieran oprimir su libertad o entrañar discriminación. Los pronunciamientos de la Corte IDH reconocen y amparan corrientes de opinión inicialmente minoritarias que han ganado espacios crecientes.

La normativa interamericana sigue una orientación liberal y sustenta el reconocimiento del derecho a conducir la vida conforme a las convicciones del sujeto, sin perder de vista los límites y restricciones recogidos en la propia CADH. En este punto destacan las aportaciones jurisprudenciales a propósito del respeto a la vida privada ${ }^{50}$ a las opciones del individuo para orientar su vida ${ }^{51}$ y al desarrollo de la personalidad. ${ }^{52}$ He aquí un nuevo e importante espacio para la presencia de derechos vinculados a la diversidad y la pluralidad sociales con sustento en una interpretación progresiva de los derechos humanos, que remonta concepciones tradicionales de carácter restrictivo o excluyente.

\section{PAREJAS Y FAMILIA}

En la más reciente jurisprudencia se ha sostenido el derecho a resolver libremente las relaciones de pareja y la integración de la familia, ${ }^{53}$ ámbito

50 Cfr. Tristán Donoso vs. Panamá (2009, párrafo 55); Fernández Ortega y otros...cit., párrafo 129; Rosendo Cantú y otra...cit., párrafo 119, y Atala Riffo y Niñas vs. Chile (2012, párrafo 162).

51 Cfr. I.V. vs. Bolivia (2016, párrafo 150); Atala Riffo y Niñas vs. Chile (2012, párrafo 136, y Flor Fleire vs. Ecuador, 31 de agosto de 2016, párrafo 103.

52 Cfr. Artavia Murillo y otros ("Fecundación in vitro") vs. Costa Rica (2012, párrafo 143); I.V. vs. Bolivia (2016, párrafo 152), y OC-24/17 (2017, párrafo 87).

53 Cfr. CIDH, OAS/Ser.L/V/II.rev.2, doc. 36 (2015, párrafo 330 y recomendación 83); CIDH (2017, párrafo 408); CIDH, OAS/Ser.L/V/II.170, Doc. 184 (2018, párrafo 70); Atala Riffo y Niñas vs. Chile (2012, párrafo 172-177); Forneron e hija vs. Argentina (2012, párrafo 98); OC-24/17 (2017, párrafos 182-199).

Esta obra está bajo una Licencia Creative Commons Atribución-NoComercial-SinDerivar 4.0 Internacional, IIJ-UNAM. Boletín Mexicano de Derecho Comparado, núm. 160, enero-abril de 2021, pp. 191-235. 
Esta revista forma parte del acervo de la Biblioteca Jurídica Virtual del Instituto de Investigaciones Jurídicas de la UNAM

en el que surgen preferencias que desbordan el marco tradicional del derecho civil e incluso el constitucional. ${ }^{54}$ Este asunto, que concurre a la tutela de la diversidad, suele aparecer en el examen de los derechos de quienes forman parte de las comunidades LGBTI (tema considerado por la Comisión Interamericana y la jurisprudencia del Tribunal de San José), a propósito de las uniones entre personas del mismo $\operatorname{sexo}^{55}$ y las consecuencias patrimoniales de la unión. ${ }^{56}$ La jurisprudencia interamericana, que analizó bajo criterios de pluralidad la composición familiar de miembros de grupos indígenas,${ }^{57}$ ha seguido la misma orientación en otros ámbitos que recientemente adquirieron visibilidad.

Esa jurisprudencia no ha rechazado la unión entre personas del mismo sexo bajo fórmulas o figuras jurídicas propias, pero también ha postulado la aplicación a esas uniones de las figuras tradicionales o generales: matrimonio, con los efectos jurídicos que derivan de éste. ${ }^{58}$ Se favorece la generalización de tales figuras con el doble propósito de evitar la formación de compartimientos jurídicos innecesarios y brindar mayor protección a los derechos de la pareja o de los integrantes de la familia.

\section{TEMAS DE BIOÉTICA}

Merecen referencia los desarrollos de la jurisprudencia interamericana sobre problemas de la agenda bioética, tomando en cuenta los diversos planteamientos éticos de grupos que coexisten en la misma comunidad nacional. En otro lugar (supra, VI) aludí a la fecundación artificial, que se

54 La definición clásica del matrimonio figura en algunas constituciones de la región: Colombia (art. 42); Venezuela (art. 77); Ecuador (art. 67); Bolivia (art. 63), y Paraguay (art. 51).

55 Cfr. OC-24/17 (2017, opinión 6 y 8), y CIDH, Informe 122/18 (2018, párrafos 185-188).

56 Cfr. CIDH, OEA/SEer.L/v/11.170 Doc.184 (2018, párrafos 218-223), y Duque vs. Colombia (2016, párrafos 124-125); OC-24/17 (2017, opinión 7).

57 Cfr. Aloeboetoe y otros vs. Surinam (1993, párrafo 17 y 62). Asimismo, el artículo XVII de la Declaración Americana sobre los Derechos de los Pueblos Indígenas reconoce el derecho que tienen los pueblos indígenas de "preservar, mantener y promover sus propios sistemas de familia".

58 Cfr. CIDH, OEA/SEer.L/v/11.170 Doc.184 (2018, párrafos 235-238), y OC-24/17 (2017, párrafo 224). Igualmente, cfr. Beatriz Gimeno (2007, pp. 177 y ss). 
Esta revista forma parte del acervo de la Biblioteca Jurídica Virtual del Instituto de Investigaciones Jurídicas de la UNAM

vincula con el derecho a la protección de la vida, el derecho a la familia y la superación de obstáculos que derivan de una discapacidad o plantean condiciones y barreras para la vida y el desarrollo de quienes la padecen (cfr. Artavia Murillo y otros vs. Costa Rica, 2012, párrafos 288-293). En este último supuesto se encuentran los problemas determinados por la presencia de alguna enfermedad o condición de riesgo que teme o reprueba la mayoría de la sociedad, como el síndrome de inmunodeficiencia adquirida. (Cffr. Gonzáles Lluy y otros vs. Ecuador, 2015, párrafos 236-240)

Añadamos la tutela del principio de autonomía en la relación médicopaciente, que también interesa dentro del estudio de la pluralidad y la diversidad de opiniones, por cuanto puede implicar decisiones diferentes de las que sustenta o recomienda la mayoría ${ }^{59} \mathrm{El}$ ejercicio eficaz de esa autonomía tiene implicaciones en el derecho a la información, ${ }^{60}$ cuyas características ha definido la jurisprudencia interamericana siguiendo las tendencias prevalecientes en esta materia.

\section{DEMOCRACIA Y DERECHOS POLÍTICOS}

Por supuesto, la orientación de la normativa interamericana hacia el reconocimiento y la protección de la diversidad y la pluralidad se ha manifestado en el ámbito de los derechos políticos ${ }^{61} \mathrm{y}$ de otros derechos asociados a la marcha general de la sociedad, entre ellos los vinculados con la libertad de expresión, a la que aludí supra VI. Unos y otros juegan un papel de primer orden en el escenario del Estado constitucional y de las garantías inherentes a una sociedad democrática. ${ }^{62}$

59 Cfr. I.V.vs. Bolivia (2016, párrafos 160-161).

60 Cfr. CIDH, OEA/Ser.L/V/II.152 (2014, párrafos 108 y ss.); I.V. vs. Bolivia (2016, párrafos 155 y ss.), y Poblete Vilches y otros vs. Chile (2018, párrafos 161 y ss).

61 Los Estados pueden regular derechos políticos, sin vulnerar los contenidos mínimos que establece la CADH. No se impone un sistema electoral o una forma específica de ejercer el derecho a votar o ser votado. Algunos grupos (así, los pueblos indígenas) pueden adoptar formas propias de designación de candidatos, tomando en cuenta sus propios usos, costumbres y tradiciones. Cfr. Yatama vs. Nicaragua (2005, párrafo 215-219), y Castañeda Gutman vs. México (2008, párrafo 166).

62 En el marco de estas reflexiones, conviene considerar el impacto que pudieran tener los pronunciamientos de la Corte IDH acerca de algunos extremos de la llamada "justicia transicional", que implica tensión entre decisiones tradicionales sobre tutela de los dere- 
Esta revista forma parte del acervo de la Biblioteca Jurídica Virtual del Instituto de Investigaciones Jurídicas de la UNAM

En este espacio de consideraciones, el orden jurídico interamericano de los derechos humanos reconoce y respeta la existencia (coexistencia) de diversas culturas con sus propios valores, requerimientos y expectativas. Aquéllas, frecuentemente ignoradas, rechazadas o subordinadas, emergen con fuerza en el nuevo marco de los derechos humanos, que lejos de imponer visiones unitarias, hegemónicas, procura el rescate de los grupos y sus culturas en el gran conjunto social. El proceso intercultural garantiza el pluralismo y respeta la diversidad. Explícita o implícita, esta idea rige en la normativa, la jurisprudencia y la doctrina más avanzada de nuestra región. ${ }^{63}$ Adelante volveré sobre algunas expresiones de este proceso en la recepción y defensa de las culturas "profundas" de los pueblos americanos.

En esa normativa y en su aplicación por los órganos del Sistema y las instancias domésticas no se autoriza ni alienta la militancia del Estado para promover o favorecer cierta convicción o ideología, en detrimento de las ideas o convicciones de algunos individuos o sectores de la sociedad. ${ }^{64} \mathrm{Al}$ ocuparse de estas cuestiones, los órganos del Sistema se han sobre el respeto a los valores y principios propios de la sociedad democrática.

Este favorecimiento implica tanto la defensa activa de la democracia (formal e integral, en los términos de la Carta Democrática Interamericana, a la que ya me referí) como el rechazo a tentaciones autoritarias que menoscaben aquellos valores y principios o entrañan alguna opresión sobre quienes sustentan opiniones diferentes de las que comparte o se pretende que comparta la mayoría.

Los derechos individuales se hallan limitados por el interés general, en los términos de la GADH (art. 32, inciso 2), pero esa limitación no entraña militancia que favorezca determinada convicción o desfavorezca otra. Desde luego, se proscriben los mensajes de odio, ${ }^{65}$ y no se ignora

chos humanos, la justicia y la democracia, y disposiciones encaminadas a resolver conflictos internos y establecer la paz. Cfr. Sergio García Ramírez (2017, p. 45), y Humberto A. Sierra Porto (2016, pp. 82 y ss).

63 Por ejemplo, cfr. Comunidad Indígena Xákmok Kásek vs. Paraguay (2010, párrafo 146), y Pueblo Indígena Kichwa de Sarayaku vs. Ecuador (2012, párrafos 219-220).

64 Cfr. OC-24/17 (2017, párrafo 223).

65 "Estará prohibida por la ley toda propaganda en favor de la guerra y toda apología del odio nacional, racial o religioso que constituyan incitaciones a la violencia o cualquier 
Esta revista forma parte del acervo de la Biblioteca Jurídica Virtual del Instituto de Investigaciones Jurídicas de la UNAM

la orientación finalista inherente al derecho a la educación, acogida en instrumentos mundiales y regionales ${ }^{66}$ orientación nutrida por el respeto a la dignidad humana, a los derechos y libertades que derivan de éste - en favor de individuos y grupos - y al imperio de la sociedad democrática.

La Corte IDH ha emitido decisiones claras asociadas a temas de religión o de convicción moral ${ }^{67}$ como vimos en líneas anteriores, e igualmente ha salido al paso de las expresiones o actuaciones de autoridades que desbordan su propia competencia o generan divisiones o enfrentamientos en el seno de la sociedad. Estas tensiones divisionistas implican un grave menoscabo para el respeto a la pluralidad ${ }^{68}$ y entrañan lesión o peligro para individuos y grupos.

\section{TENSIÓN ENTRE ÓRDENES NORMATIVOS}

La normativa interamericana recibe los imperativos sobre derechos humanos derivados de la ley interna y los tratados internacionales, y reconoce la posibilidad de acoger derechos inherentes al ser humano no previstos en el estatuto interamericano $\left(\mathrm{CADH}\right.$, art. 29, b) ${ }^{69}$ Éste es el "piso", no el "techo", de los derechos fundamentales. Ya señalamos - y adelante reite-

otra acción ilegal similar contra cualquier persona o grupo de personas, por ningún motivo, inclusive los de raza, color, religión, idioma u origen nacional". CADH (art. 13.5). Asimismo, $c f r$ CIDH, OAS/Ser.L/V/II.rev.2 (2015, párrafos 214 y ss.).

66 La "educación deberá orientarse hacia el pleno desarrollo de la personalidad humana y del sentido de su dignidad y deberá fortalecer el respeto por los derechos humanos, el pluralismo ideológico, las libertades fundamentales, la justicia y la paz". "Protocolo de San Salvador", artículo 13; asimismo, Cfr. Pacto Internacional de Derechos Económicos, Sociales y Culturales, 16 de diciembre de 1966, artículo 13, y Protocolo adicional al Convenio Europeo para la Protección de los Derechos Humanos y de las Libertades Fundamentales, 20 de marzo de1952 (art. 2).

67 La Comisión Interamericana también ha conocido de algunos casos relativos a esta problemática, por ejemplo, Cfr. CIDH, Informe 43/05. (2005, párrafos 84 y ss.).

68 Cfr. CIDH, Institucionalidad democrática, Estado de derecho y derechos humanos en Venezuela, OEA/Ser.L/V/II., 31 diciembre 2017, párrafo 233; Apitz Barbera y otros ("Corte Primera de lo Contencioso Administrativo") vs. Venezuela, 5 de agosto de 2008, párrafo 131, y Perozo y otros vs. Venezuela, 28 de enero de 2009, párrafo 151.

69 Cfr. CADH, artículo 29, b). Sobre este tema, Cfr. Martin, Claudia, "La mobilisation des sources extérieures par la Cour Interaméricaine des droits de l'homme. L'exemple du droit à la vie", en Varios, Les défis de l'interprétation et l'application des droits de l'homme. Del l'ouverture au dialogue, Paris, Éditions A. Pedone, 2017, pp. 243 y ss.

Esta obra está bajo una Licencia Creative Commons Atribución-NoComercial-SinDerivar 4.0 Internacional, IIJ-UNAM. Boletín Mexicano de Derecho Comparado, núm. 160, enero-abril de 2021, pp. 191-235. 
Esta revista forma parte del acervo de la Biblioteca Jurídica Virtual del Instituto de Investigaciones Jurídicas de la UNAM

raré - que en el marco del Sistema Interamericano tienten presencia los derechos enunciados por diversos instrumentos que consideran situaciones vinculadas con la diversidad o la pluralidad en el seno de la sociedad, como pueden ser las relacionadas con el estatus migratorio, la pertenencia a pueblos indígenas o la discapacidad.

Como ya se dijo a propósito de la eficacia de los derechos específicos en los que se refleja la pluralidad social, el orden interamericano (principalmente las sentencias de la Corte IDH) sostiene la vigencia y aplicación de órdenes normativos especiales, emanados de grupos o sectores de la sociedad: derecho consuetudinario, usos y costumbres, que deben ser respetados y garantizados por el Estado nacional..$^{70}$ En este sentido, ingresa al orden normativo lo que se ha llamado "derecho social de creación autónoma” (Sergio García Ramírez, 1965, pp. 636-639), que muestra diversas vertientes, entre las que figuran, por lo que toca a la materia del presente trabajo, las correspondientes a derechos humanos.

Aun cuando no se han creado un régimen especial o instancias destinadas a la solución de tensiones o conflictos entre disposiciones generales y normas de grupos específicos, la Corte IDH es competente para resolver litigios de esta naturaleza, o bien, para remitir la solución a instancias nacionales una vez que se ha pronunciado sobre la violación de derechos y la reparación a las víctimas. ${ }^{71}$ Esta competencia resolutiva final (irrecurrible) o el reenvío a la jurisdicción interna implican una legítima injerencia del órgano supranacional en cuestiones cuya atención inicial pudiera corresponder, en principio, al orden jurídico doméstico.

Surge aquí cierta consideración jerárquica (aunque es posible emplear otros términos para caracterizar el enlace entre la justicia interna y la supranacional) ${ }^{72}$ en virtud de que la resolución final compete al órgano supranacional cuando la contienda atañe precisamente a derechos huma-

70 Cfr. Pueblo Indígena Kichwa de Sarayaku vs. Ecuador (2012, párrafos 55 y 264), y Comunidad Indigena Yakye Axa vs. Paraguay (2005, párrafo 63).

71 Cfr. Trabajadores Cesados del Congreso (Aguado Alfaro y otros) vs. Perú (2006, párrafos 148149); Castañeda Gutman vs. México (2008, párrafo 231), y Asociación Nacional de Cesantes y Fubilados de la Superintendencia Nacional de Administración Tributaria (ANCEJUB-SUNAT) vs. Perú (2019, párrafo 225-226).

72 La Suprema Corte de Justicia de México ha denominado a este enlace "parámetro de regularidad constitucional”. Cfr. Contradicción de Tesis 293/2011 (2013, p. 41). 
Esta revista forma parte del acervo de la Biblioteca Jurídica Virtual del Instituto de Investigaciones Jurídicas de la UNAM

nos. ${ }^{73}$ La atribución de esta competencia al juzgador supranacional no supone una tercera o cuarta instancia a cargo de éste, ${ }^{74}$ ni suprime la autonomía de las jurisdicciones internas generales o especiales. ${ }^{75}$

Las instancias regionales de supervisión reconocen la necesaria interacción entre diversos órdenes normativos (Diego García-Sayán, 2005, pp. 325-330). Como dije, hay temas en los que se abre la posibilidad de concurrencia de decisiones de órganos internacionales y órganos internos, que a su vez deben tomar en cuenta las modalidades domésticas de protección de derechos humanos correspondientes a miembros de grupos o sectores específicos, lo cual implica el reconocimiento eficaz de la pluralidad social.

\section{PRO PERSONA Y OTROS PRINCIPIOS ESPECÍfICOS}

En sus propias decisiones, la jurisdicción interamericana ha desarrollado principios derivados de instrumentos internacionales, ${ }^{76}$ desarrollo que pue-

73 "El fallo de la Corte será definitivo e inapelable. En caso de desacuerdo sobre el sentido o alcance del fallo, la Corte lo interpretará a solicitud de cualquiera de las partes, siempre que dicha solicitud se presente dentro de los noventa días a partir de la fecha de la notificación del fallo". CADH (art. 67). Igualmente, cfr. Apitz Barbera y otros ("Corte Primera de lo Contencioso Administrativo") vs. Venezuela (2012, párrafos 21 y 22), y Fontevecchia y D’Amico vs. Argentina (2017, párrafo 13).

74 Cfr. Cabrera García y Montiel Flores vs. México (2010, párrafo 16); Palma Mendoza y otros vs. Ecuador (2012, párrafo 18), y Tarazona Arrieta y otros vs. Perú (2014, párrafo 22).

75 Cfr. Sergio García Ramírez (2012, p 18), y Voto razonado del juez Eduardo Ferrer Mac-Gregor Poisot en Gelman vs. Uruguay, Supervisión de Cumplimiento de Sentencia (2013, párrafos 43-66).

76 Para la comunidad LGBTI se han utilizado los Principios de Yogyakarta, cfr. OC24/17 (2017, párrafo 112). Acerca de casos relacionados con pueblos indígenas se ha utilizado el Convenio 169 de la Organización Internacional del Trabajo. Cfr. Comunidad Garifuna de Punta Piedra y sus miembros vs. Honduras (2015, párrafos 91 y ss.). En relación con casos de niñas, niños y adolescentes la Corte IDH ha utilizado y mencionado la Convención sobre los Derechos del Niño. Cfr. Ramírez Escobar y otros vs. Guatemala (2018, párrafo 149. A propósito de personas con discapacidad se ha utilizado la Convención sobre los Derechos de las Personas con Discapacidad. Cfr. Chinchilla Sandoval vs. Guatemala (2016, párrafo 205 y ss.). En lo que respecta a la violencia hacia la mujer se ha utilizado la Convención sobre la eliminación de todas las formas de discriminación contra la mujer, así como los informes del Comité para la Eliminación de la Discriminación contra la Mujer de las Naciones Unidas. Cfr. Velásquez Paiz y otros vs. Guatemala (2015, párrafo 175).

Esta obra está bajo una Licencia Creative Commons 
Esta revista forma parte del acervo de la Biblioteca Jurídica Virtual del Instituto de Investigaciones Jurídicas de la UNAM

de significar una interpretación pretoriana pro persona (Eduardo Ferrer, 2017, pp. 197 y ss.). A este respecto, vale citar las decisiones tutelares de grupos indígenas, mujeres, niños, discapacitados y miembros de las comunidades LGBTI.

La doctrina ha observado que en forma paralela y por vía de aplicación del principio pro persona se abre paso la aplicación de principios específicos de protección: pro mulier, pro niño, pro indígena, pro discapacitado, pro anciano, pro migrante, etcétera. Cada uno de estos principios constituye el dato rector y la referencia suprema para el reconocimiento y la interpretación de los derechos y libertades de los individuos que integran diversos grupos o sectores sociales.

\section{IDENTIDAD PERSONAL}

Como se sugiere en el documento-cuestionario de los relatores generales mencionado en nota al preámbulo de este artículo, el concepto de diversidad acoge la existencia de múltiples identidades: nacionales, étnicas, culturales, lingüísticas, religiosas, sexuales y otras, con los derechos correspondientes al efectivo ejercicio de aquéllas. La orientación general y creciente del orden jurídico interamericano, expresada en lineamientos diversos, recomendaciones, sentencias y opiniones consultivas favorece enfáticamente el reconocimiento de esas diversas identidades, que a su vez quedan bajo la protección de los deberes generales de respeto y garantía. Compete al individuo, en ejercicio de su libertad, resolver sobre la identidad que desee asumir (pertenencia a grupos o comunidades LGBTI o indígenas, por ejemplo; también, elección de nombre propio). ${ }^{77}$

La asunción de cierta identidad, que puede ser estrictamente individual o significar la integración del individuo en determinado grupo o sector, compete al interesado. La jurisprudencia interamericana asocia la elección de identidad con el derecho a la libertad y al respeto a la vida privada. ${ }^{78}$ Esto aporta caracterizaciones cada vez más amplias de la liber-

77 Cfr. CIDH, OEA/Ser.L/V/II (párrafo 31); OAS/Ser.L/V/II (2019, párrafos 21-22), Comunidad Indígena Xákmok Kásek vs. Paraguay (2010, párrafo 37), Flor Freire vs. Ecuador (2016, párrafos 120-121), y OC-24/17 (2017, párrafos 95, 105, 106, 115 y 116).

78 Cfr. OC-24/17 (2017, párrafos 87-90), y Federico Andreu-Guzmán (2019, pp. 119 $120)$.

Esta obra está bajo una Licencia Creative Commons

Atribución-NoComercial-SinDerivar 4.0 Internacional, IIJ-UNAM.

Boletin Mexicano de Derecho Comparado, núm. 160, enero-abril de 2021, pp. 191-235. 
Esta revista forma parte del acervo de la Biblioteca Jurídica Virtual del Instituto de Investigaciones Jurídicas de la UNAM

$\operatorname{tad}^{79}$ y medidas cada vez más protectoras de su efectivo ejercicio, con las importantes consecuencias en distintos órdenes: familiar, laboral, patrimonial, por ejemplo, hacia los que se proyectan la pluralidad social y las opciones individuales.

\section{ESTADO GARANTE}

Los portadores de las identidades particulares son titulares de todos los derechos, generales y especiales, vinculados a su condición humana y a su elección identitaria. Frente a esa titularidad de derechos, se afirman los deberes generales y especiales de los Estados (garantes genéricos de los derechos y libertades de todos los individuos colocados bajo su jurisdicción, y garantes específicos en situaciones de vulnerabilidad personal).

Esta garantía específica, que la jurisprudencia interamericana proyecta sobre amplios sectores de la población —así, los niños, los enfermos mentales, los reclusos - ${ }^{80}$ puede aplicarse directamente a los integrantes de grupos o sectores con características, opciones o decisiones diferentes de los que prevalecen en la mayoría de la sociedad, y por ello constituye un factor relevante para la tutela de los derechos asociados a la pluralidad y la diversidad. Es aquí donde ocurre el benéfico encuentro entre grupos y sectores minoritarios o vulnerables a los que se reconocen derechos genéricos y específicos, y el poder público obligado a garantizar el ejercicio de aquéllos.

Las reglas especiales de tratamiento a cargo del Estado se vinculan con múltiples extremos conducentes al despliegue de la identidad para la práctica de derechos, ${ }^{81}$ entre ellos los relativos a las relaciones familia-

79 La Corte "ha interpretado en forma amplia el artículo 7 de la Convención Americana al señalar que éste incluye un concepto de libertad en un sentido extenso como la capacidad de hacer y no hacer todo lo que esté lícitamente permitido. En otras palabras, constituye el derecho de toda persona de organizar, con arreglo a la ley, su vida individual y social conforme a sus propias opciones y convicciones". Gelman vs. Uruguay (2011, párrafo 129), y Artavia Murillo y otros (Fecundación in Vitro) vs. Costa Rica (párrafo 142).

80 Cfr. "Instituto de Reeducación del Menor" vs. Paraguay (2004, párrafo 160); Ximenes Lopes vs. Brasil (2006, párrafo 138), y Chinchilla Sandoval y otros vs. Guatemala (2016, párrafo 168 ).

81 Cfr. Niñas Yean y Bosico vs. República Dominicana (2005, párrafos 142, 166, 167, 179 y 185), y OC-24/17 (2017, párrafo 90). 
Esta revista forma parte del acervo de la Biblioteca Jurídica Virtual del Instituto de Investigaciones Jurídicas de la UNAM

res, el respeto a las prácticas ancestrales, el acceso a la justicia y la asunción de funciones públicas (participación en el poder formal e informal), despliegue que a su vez desecha formas de exclusión o discriminación. ${ }^{82}$

La condición de garante que incumbe al Estado se proyecta tanto en las obligaciones de hacer o de omitir por parte de los órganos y agentes del poder público, como en la tutela de los individuos frente a las vulneraciones que pudieran derivar de la conducta activa u omisiva de otros particulares. ${ }^{83}$ Estas afirmaciones tienen sustento en instrumentos regionales y en resoluciones de los órganos supranacionales de protección. ${ }^{84}$ Desde luego, la elección de cierta identidad ha de fundarse en consideraciones de hecho que le brinden sustento razonable. (Flor Freire vs. Ecuador, 2016, párrafos 103 y 121)

\section{DERECHO COMÚN REgIONAL Y ESTATUTOS ESPECIALES}

La normativa interamericana se ha propuesto asegurar el imperio generalizado de los derechos humanos, bajo reglas de interpretación compartidas, consecuentes con la pretensión de generar un jus commune regional. ${ }^{85}$ A este propósito y en atención a las condiciones propias del mundo americano, todavía asediado por reticencias u oposiciones, obedece la distancia que se

82 Cfr. Aloeboetoe y otros vs. Surinam (1993, párrafos 17 y 62); Katama vs. Nicaragua (2005, párrafo 215), Masacres de Río Negro...cit., párrafos 153-165; Rosendo Cantú y otra vs. México (2010, párrafo 184-185); Atala Riffo y Niñas vs. Chile (2012, párrafo 172-177); Forneron e hïa vs. Argentina (2012, párrafo 98), y OC-24/17 (2017, párrafos 182-199).

83 Cfr. OC-18/03 (2003, párrafos 100 y 104); Valle Faramillo y otros vs. Colombia (2008, párrafo 77), y López Soto y otros vs. Venezuela (2018, párrafos 138-140).

84 "Convención de Belem do Para" (art. 7); Convención Interamericana contra Toda Forma de Discriminación e Intolerancia (art. 4); Convención Interamericana contra el Racismo, la Discriminación Racial y Formas Conexas de Intolerancia (art. 4); CIDH, Maria da Penha Maia Fernandes, Brasil (2001, párrafos 55-58); Velásquez Rodríguez...cit., párrafo 172, y OC-18/03 (2003, párrafo 141).

$85 \mathrm{El}$ jus commune "se refiere a un enfoque regional sobre el constitucionalismo transformador. Dicho enfoque se nutre de la inquietante experiencia respecto de condiciones de vida inaceptables y apunta a la transformación de la realidad política y social de América Latina por medio del fortalecimiento concertado de la democracia, el Estado de derecho y los derechos humanos" (Armin von Bogdandy, 2015, p. 3); del mismo autor, cfr. (2014).

Esta obra está bajo una Licencia Creative Commons

Atribución-NoComercial-SinDerivar 4.0 Internacional, IIJ-UNAM.

Boletin Mexicano de Derecho Comparado, núm. 160, enero-abril de 2021, pp. 191-235. 
Esta revista forma parte del acervo de la Biblioteca Jurídica Virtual del Instituto de Investigaciones Jurídicas de la UNAM

mantiene frente a la idea de un margen nacional de apreciación, que en otra región constituye un principio ampliamente recibido. ${ }^{86}$

Como hemos visto, el reconocimiento del derecho a la diversidad y al ejercicio de la propia identidad en el marco de la libertad, todo ello dentro de la sociedad plural y democrática, implica capacidad normativa por parte de grupos o sectores de la sociedad. El Sistema Interamericano ha reconocido el derecho de éstos a participar en la emisión de las normas que regulan su existencia y la actividad de sus integrantes, que anteriormente se mencionó. ${ }^{87}$ Esta competencia normativa no excluye la vigencia de los derechos humanos, ${ }^{88}$ que son el límite de los órdenes jurídicos específicos, ni implica la erosión o supresión de las sociedades nacionales.

Un tema relevante para estas consideraciones es el acceso de los individuos integrantes de grupos o sectores especiales a las instancias del poder público (cfr. Yatama vs. Nicaragua, 2005, párrafos 215-217 y Laurence Burgorgue-Larsen y Amaya Úbeda de Torres, 2009, pp. 658 y ss.). Los derechos políticos se hallan a salvo de suspensiones, incluso en casos de emergencia o grave perturbación del orden: forman parte del "núcleo duro" de los derechos fundamentales. ${ }^{89}$

$\mathrm{Al}$ amparo del Sistema Interamericano - derecho convencional y aplicaciones jurisdiccionales - los indígenas pueden participar por vías propias en la adopción de decisiones políticas, inclusive fuera de los cauces partidarios tradicionales (Yatama vs. Nicaragua, 2005, párrafos 201224). La jurisprudencia ha dejado en el ámbito de los Estados nacionales la decisión sobre procedimientos electorales, pero ha declarado que éstos deben ser congruentes con los requerimientos de representación y actua-

86 Cfr. Javier García Roca (2010); Mireille (2006, p. 78); Néstor P. Sagües (2016, pp. 48 y ss.), y Laurence Burgorgue-Larsen (2013, p. 27).

87 Cfr. CIDH, OEA/Ser.L/V/II (2007, párrafo 293); OEA/Ser.L/V/II. Doc. 65 (2011, párrafo 200), y OEA/Ser.L/V/II. Doc.44/17 (2017, párrafos 172-174).

88 "Los pueblos indígenas tienen derecho a promover, desarrollar y mantener sus estructuras institucionales y sus propias costumbres, espiritualidad, tradiciones, procedimientos, prácticas y, cuando existan, costumbres o sistemas jurídicos, de conformidad con las normas internacionales de derechos humanos". Declaración Americana sobre los Derechos de los Pueblos Indígenas (art. XXll, inciso 1). Asimismo, CIDH, OEA/Ser.L/V/II. Doc.44/17 (párrafos 176 y 181).

89 Cfr. Sergio García Ramírez (2016b, p. 355); Opinión Consultiva OC-6/86, (1986, párrafo 34); Yatama vs. Nicaragua. (2005, párrafo 191), y Castañeda Gutman vs. México (2008, párrafo 140). 
Esta revista forma parte del acervo de la Biblioteca Jurídica Virtual del Instituto de Investigaciones Jurídicas de la UNAM

ción propios de la sociedad democrática; en otros términos, la adopción de métodos o fórmulas de participación compete al derecho doméstico, pero éste debe atender la orientación de la normativa supranacional sustentada en los valores y principios de la democracia, de manera que se logre el más amplio ejercicio de los derechos del individuo. (Cfr. Castañeda Gutman vs. México, 2008, párrafo 140)

\section{Derechos ECONÓMICOS, SOCIALES, GULTURALES Y AMBIENTALES}

Amerita referencia especial la jurisprudencia más reciente de la Corte IDH, que judicializa derechos económicos, sociales, culturales y ambientales, a cuyo desarrollo progresivo se refiere el artículo 26 de la CADH. ${ }^{90}$ Anteriormente, la tutela de algunos derechos de esta categoría se llevaba a cabo a través de la protección de derechos civiles y políticos (por ejemplo: derecho a la protección de la salud, considerado a la luz de la protección del derecho a la integridad). ${ }^{91}$ La interpretación mayoritaria que hoy prevalece sostiene la justiciabilidad directa de aquellos derechos con sustento en la Carta de la OEA y en el orden jurídico nacional e internacional. ${ }^{92}$

90 "Los Estados Partes se comprometen a adoptar providencias, tanto a nivel interno como mediante la cooperación internacional, especialmente económica y técnica, para lograr progresivamente la plena efectividad de los derechos que se derivan de las normas económicas, sociales y sobre educación, ciencia y cultura, contenidas en la Carta de la Organización de los Estados Americanos, reformada por el Protocolo de Buenos Aires, en la medida de los recursos disponibles, por vía legislativa u otros medios apropiado" (CADH, art. 26). Desarrollo progresivo, sobre este tema, $c f$ r. Víctor Abramovich y Christian Courtis (2014); Sergio García Ramírez (2003, pp. 127-157); Víctor Bazán y Luis Jimena Quesada (2014, pp. 179-182), y Laurence Burgorgue-Larsen y Amaya Úbeda de Torres (2011, pp. 627 y ss.).

91 Cfr. Comunidad Indígena Yakye Axa vs. Paraguay (2005, párrafos 162 y ss.), Ximenes Lopes vs. Brasil (2006, párrafos 124 y ss.), Vera Vera y otra vs. Ecuador (2011, párrafos 43-44); Comunidad Indígena Xákmok Kásek vs. Paraguay (2010, párrafos 194-217); Suárez Peralta vs. Ecuador (2013, párrafo 131), y Gonzales Lluy y otros vs. Ecuador (2015, párrafos 167 y ss.).

92 Cfr. Lagos del Campo vs. Perú (2017); Trabajadores Cesados de Petroperú y otros vs. Perú (2017); San Miguel Sosa y otra vs. Venezuela (2018); Poblete Vilches y otros vs. Chile (2018); Cuscul Pivaral y otros vs. Guatemala (2018), y Muelle Flores vs. Perú (2019). Este criterio no ha sido unánime entre los integrantes de la Corte IDH, $c f r$. votos parcialmente disidentes del juez Humberto Sierra Porto en los casos Muelle Flores vs. Perú, Guscul Pivaral y otros vs. Guatemala, Poblete Vilches y otros vs. Chile, San Miguel Sosa y otras vs. Venezuela, Trabajadores Cesados

Esta obra está bajo una Licencia Creative Commons

Atribución-NoComercial-SinDerivar 4.0 Internacional, IIJ-UNAM.

Boletín Mexicano de Derecho Comparado, núm. 160, enero-abril de 2021, pp. 191-235. 
Esta revista forma parte del acervo de la Biblioteca Jurídica Virtual del Instituto de Investigaciones Jurídicas de la UNAM

Evidentemente, esta interpretación se puede proyectar inmediatamente sobre los diversos grupos y sectores de la sociedad. (Cfr. Eduardo Ferrer MacGregor 2017, pp. 206 y ss.)

\section{CONCLUSIÓN: DEBERES DEL ESTADO}

En los términos de los párrafos anteriores - especialmente lo dicho sub XIII, supra - , se confirma la hipótesis adelantada al inicio de este trabajo y queda claro que los Estados que figuran en el Sistema Interamericano - y especialmente los que son parte de la normativa convencional y han reconocido la competencia contenciosa de la jurisdicción regional - están obligados a brindar respeto y garantía a los derechos de quienes se hallan sujetos a su jurisdicción y forman parte de grupos o sectores específicos de la sociedad: en este punto concurren y se resuelven los imperativos de la igualdad y la especificidad.

Asimismo, los Estados deben adoptar las medidas necesarias para el ejercicio de aquellos derechos, medidas que tienen gran alcance: jurídico y de otra naturaleza, ${ }^{93}$ y que se proyectan inmediatamente sobre el desempeño de los órganos estatales y mediatamente sobre la conducta de los particulares. En este sentido, los Estados deben emitir disposiciones jurídicas específicas y procurar la remoción de obstáculos sociales (modificaciones culturales) ${ }^{94}$ para asegurar la protección de los derechos inherentes a la diversidad y pluralidad social.

de Petroperú y otros vs. Perú, Lagos del Campo vs. Perú y Gonzales Lluy y otros vs. Ecuador (2015). Además, cfr. votos del juez Eduardo Vio Grossi en los casos Muelle Flores vs. Perú, San Miguel Sosa y otras vs. Venezuela, Trabajadores Cesados de Petroperú y otros vs. Perú y Lagos del Campo vs. Perú.

93 "Si el ejercicio de los derechos y libertades mencionados en el artículo 1 no estuviere ya garantizado por disposiciones legislativas o de otro carácter, los Estados partes se comprometen a adoptar, con arreglo a sus procedimientos constitucionales y a las disposiciones de esta Convención, las medidas legislativas o de otro carácter que fueren necesarias para hacer efectivos tales derechos y libertades". (CADH, art. 2).

94 Cfr. González y otras ("Campo Algodonero") vs. México (2009, párrafos 450 y 541-543); Veliz Franco y otros vs. Guatemala (2014, párrafo 275); Velásquez Paiz y otros vs. Guatemala (2015, párrafo 248); Fernández Ortega y otros vs. Panamá (2009, párrafos 260 y 262=; Rosendo Cantú y otra vs. México (2010, párrafos 245-246 y 249), y Mujeres víctimas de tortura sexual en Atenco (2018, párrafo 218-219). 
Esta revista forma parte del acervo de la Biblioteca Jurídica Virtual del Instituto de Investigaciones Jurídicas de la UNAM

A su vez, los individuos pueden exigir la observancia de sus derechos tanto a través de recursos ante los órganos nacionales obligados a atender los mandamientos internacionales y a ejercer, conforme a su competencia, el control de convencionalidad, como por la vía de la tutela internacional contemplada por los tratados del Sistema, en los términos previstos en éstos.

La homogeneidad propia de las sociedades nacionales no impide la natural heterogeneidad en el seno de esas sociedades, consecuente con la libertad y la democracia. Y esa heterogeneidad sustenta - justifica y reclama - normas y medidas especiales que amparen los derechos de individuos, grupos y sectores, sin minar al conjunto de la sociedad y complementando los imperativos de la igualdad con los de la especificidad, que aportan novedades importantes y garantizan, en definitiva, el desarrollo de la personalidad.

El hecho de que los derechos específicos de individuos, grupos o sectores integrados en la sociedad heterogénea, diversa y plural se hallen enmarcados por el derecho internacional de los derechos humanos, y de que éste informe el derecho común interamericano, implica la necesidad de compatibilizar, conciliar o armonizar los órdenes especiales con el orden general de aquellos derechos. ${ }^{95}$ Este proceso de armonización no implica supresión o abolición de los regímenes particulares, sino convergencia entre éstos y el régimen general bajo valores y principios compartidos y con respeto a las facultades que entrañan la libertad y la autonomía a las que nos hemos referido en líneas precedentes. ${ }^{96}$

La normativa interamericana y los criterios sustentados por los órganos regionales de protección de los derechos humanos han tenido muy importante repercusión sobre el orden jurídico de varios Estados del ámbito

95 Cfr. CIDH, OEA/Ser.L/V/II. Doc.44/17 (párrafos 174, 180-181), y Situación de los derechos humanos de los pueblos indígenas...cit., párrafos 43-45.

96 En alguna ocasión la Corte ha atendido la voluntad de la víctima en relación con medidas que generalmente adopta para la protección y el desarrollo de aquélla, cuando pudieran resultar inconvenientes en función del ambiente cultural y las costumbres que prevalecen en el medio en el que la víctima se desenvuelve. Cfr., por ejemplo, Rosendo Cantú y otra vs. México (2010, párrafos 213 y 229), y Fernández Ortega y otros vs. Panamá, (2009), párrafos 244, 247, 259, 262 у 267. 
Esta revista forma parte del acervo de la Biblioteca Jurídica Virtual del Instituto de Investigaciones Jurídicas de la UNAM

latinoamericano. ${ }^{97} \mathrm{La}$ influencia del derecho interamericano y de otras fuentes del sistema universal o regional de los derechos humanos se refleja en textos constitucionales y legales, en la proclamación de diversas políticas públicas y en la cada vez más abundante jurisprudencia de tribunales supremos y otros órganos jurisdiccionales de esta región. ${ }^{98}$ La recepción interna del ordenamiento internacional constituye un hecho relevante en el progreso jurídico de varios países y en el avance de la tutela de los derechos humanos, que ya es interesante, aunque debiera ser mayor.

Este proceso de recepción de criterios externos, provenientes tanto del orden interamericano como de las aportaciones de otros sistemas de tutela - especialmente el sistema mundial, por medio de diversas instancias - se manifiesta en los temas examinados en este trabajo. Ocurre en la normativa interna sobre principios y reglas de la sociedad democrática, regulación en torno a sectores vulnerables, pueblos indígenas, trato a diversas minorías, respeto a la identidad, acceso a la justicia y rechazo y reforma de estereotipos y antiguos obstáculos para el libre desarrollo de individuos, grupos y sectores de la sociedad. Como se ha visto a lo largo del presente panorama, en estos ámbitos la normativa doméstica receptora de orientaciones provenientes de la interamericana, contribuye a la recepción, el respeto y la garantía de derechos de signo específico que conciernen a quienes forman parte de grupos diversos al amparo de la diversidad y la pluralidad imperantes en una sociedad democrática.

\section{BIBLIOGRAFÍA}

"Instituto de Reeducación del Menor" vs. Paraguay (2004). Corte IDH. Sentencia del 2 de septiembre. Ximenes Lopes vs. Brasil (2006). Corte IDH. Sentencia del 4 de julio.

97 Cfr. CIDH, OEA/Ser.L/V/II.152 (2014, párrafos 38-56); José Miguel Vivanco (2005, pp. 27-36); Loretta Ortiz Ahlf (2005, pp. 293-302), y varios autores (2006).

98 Cfr. Darío Villaroel Villaroel (2004, pp. 313 y ss. y 393 y ss.); Fernando Silva García y Juan N. Silva Meza (2009, pp. 332 y ss.); varios autores (2016, pp. 13-16); Héctor FixZamudio y Salvador Valencia Carmona (2017, pp. 552 y ss.); Víctor Rodríguez Recia (2018); varios autores (2018, pp. 3-4); Andrés Rousset Siri (2018, pp. 74 y ss.), y varios autores (2018, pp. 571 y ss.). 
Esta revista forma parte del acervo de la Biblioteca Jurídica Virtual del Instituto de Investigaciones Jurídicas de la UNAM

"La última tentación de Cristo" (Olmedo Bustos y otros) vs. Chile (2001). Corte IDH. Sentencia del 5 de febrero.

"La Última Tentación de Cristo" (Olmedo Bustos y otros) vs. Chile (2001). Corte IDH. Sentencia del 5 de febrero.

Abramovich, Víctor y Courtis, Christian (2014). Los derechos sociales como derechos exigibles. 2a. ed. Trotta.

Abramovich, Víctor y COURTis, Christian (comps.) (2006). La aplicación de los tratados sobre derechos humanos en el ámbito local. La experiencia de una década. Del Puerto-Centro de Estudios Legales y Sociales.

Aguiar Aranguren, Asdrúbal (2012). Furisprudencia de la Corte Interamericana de Derechos Humanos sobre la democracia. Observatorio Iberoamericano de la Democracia.

Alcalá-Zamora, Niceto (1974). La protección procesal internacional de los derechos humanos. En Varios autores, Veinte años de evolución de los Derechos Humanos (p. 330), México: UNAM, Instituto de Investigaciones Jurídicas.

Almonacid Arellano y otros vs. Chile (2006). Corte IDH. Sentencia del 26 de septiembre.

Aloeboetoe y otros vs. Surinam (1993). Corte IDH. Sentencia del 10 de septiembre.

Amparo directo 6/2018. Primera Sala. Suprema Corte de Justicia de la Nación. 21 de noviembre de 2019.

AnDreu-GuZmán, Federico (2019). "Artículo 3. Derecho al reconocimiento de la personalidad jurídica". En Christian STeINer y MarieChristine Fuchs (eds.). Convención Americana sobre Derechos Humanos (pp. 119-120). Konrad Adenauer Stiftung.

Apitz Barbera y otros ("Corte Primera de lo Contencioso Administrativo") vs. Venezuela (2012). Corte IDH. Supervisión de cumplimiento de sentencia. Del 23 de noviembre.

Apitz Barbera y otros ("Corte Primera de lo Contencioso Administrativo") vs. Venezuela (2008). Corte IDH. Sentencia del 5 de agosto.

Artavia Murillo y otros ("Fecundación in vitro") vs. Costa Rica (2012). Corte IDH.

Sentencia del 28 de noviembre.

Asociación Nacional de Cesantes y Jubilados de la Superintendencia Nacional de Administración Tributaria (ANCEJUB-SUNAT) vs. Perú (2019). Corte IDH.

Sentencia del 21 de noviembre.

Atala Riffo y Niñas vs. Chile (2012). Corte IDH. Sentencia del 24 de febrero.

Esta obra está bajo una Licencia Creative Commons

Atribución-NoComercial-SinDerivar 4.0 Internacional, IIJ-UNAM.

Boletín Mexicano de Derecho Comparado, núm. 160, enero-abril de 2021, pp. 191-235. 
Esta revista forma parte del acervo de la Biblioteca Jurídica Virtual del Instituto de Investigaciones Jurídicas de la UNAM

BAZÁN, Víctor y FUCHS, Marie-Christine (eds.) (2018). Fusticia constitucional y derechos fundamentales. Fusticia y política en América Latina. Konrad Adenauer.

BAZÁn, Víctor y Jimena QUESADA, Luis (2014). Derechos económicos, sociales y culturales: cómo se protegen en América Latina y en Europa.

BERIZONCE, Roberto Omar (2009). Tutelas procesales diferenciadas. RubizalCulzoni.

BOGDANDY, Armin von (2014). Ius constitutionale commune latinoamericanum. Una aclaración conceptual. Ius constitutionale commune en América Latina. Rasgos, potencialidades y desafios. Universidad Nacional Autónoma de México, Instiuto de Investigaciones Jurídicas-Max-Planck.

Bogdandy, Armin von (2015). Ius Constitutionale Commune en América Latina: una mirada a un constitucionalismo transformador. Revista Derecho del Estado (34), p. 3.

BURGORGUE-LARSEN, "Les standars, normes imposées ou consenties? En Variosautores. Existe-t-il une exception française en matière de droits fondamentaux? (p. 27). Les Cahiers de l'Institut Louis Favoreu-Aix-MarseillePUAM.

Burgorgue-Larsen, Laurence y Úbeda de Torres, Amaya (2008). Les grandes decisions de la Cour Interamericaine des Drois de L'Homme. Bruylant, pp. 649-650.

Burgorgue-Larsen, Laurence y Úbeda de Torres, Amaya (2011). The Inter-american Court of Human Rights. Case law and commentary. Oxford University Press.

Cabrera García y Montiel Flores vs. México (2010). Corte IDH. Sentencia del 26 de noviembre.

Carta Democrática Interamericana, 11 de septiembre de 2001.

Castañeda Gutman vs. México (2008). Corte IDH. Sentencia del 6 de agosto.

Chinchilla Sandoval vs. Guatemala (2016). Corte IDH. Sentencia del 29 de febrero.

Chitay Nech y otros vs. Guatemala (2010). Corte IDH. Sentencia del 25 de mayo.

GIDH (1981). Resolución 23/81. Caso 2141, Estados Unidos de América. Del 6 de marzo

CIDH (2001). Informe 04/01. Caso 11.625, Fondo, María Eugenia Morales de Sierra. Sentencia del 19 de enero. 
Esta revista forma parte del acervo de la Biblioteca Jurídica Virtual del Instituto de Investigaciones Jurídicas de la UNAM

CIDH (2001). Informe 54/01. Caso 12.051, Maria da Penha Maia Fernandes. Del 16 de abril.

CIDH (2004). Informe 75/15. Caso 12.923, Fondo, Rocío San Miguel Sosay otras vs. Venezuela. Herrera Ulloa vs. Costa Rica (2004). Corte IDH. Sentencia del 2 de julio.

CIDH (2004). Informe de Fondo 40/04, Caso 12.053, Comunidades Indígenas Mayas del Distrito de Toledo vs. Belice. Del 12 de octubre.

CIDH (2005). Informe 32/05. Petición 642/2003. Admisibilidad, Luis Ronaldo Cuscul Pivaral y otras personas afectadas por el VIH/SIDA. Del 7 de marzo de 2005.

CIDH (2005). Informe 43/05. Caso 12.219, Fondo, Gristián Daniel Sahli Vera y otros. Del 10 de marzo. CIDH (2017). OEA/Ser.L/V/II. Institucionalidad democrática, Estado de derecho y derechos humanos en Venezuela. Del 31 diciembre.

CIDH (2007). OEA/Ser.L/V/II, Doc. 34. Informe sobre acceso a la justicia e inclusión social: El camino hacia el fortalecimiento de la democracia en Bolivia. Del 28 de junio.

CIDH (2009). Informe 98/09. Petición 4355-02. Admisibilidad, Pueblo Indígena Xucuru. Del 29 de octubre.

CIDH (2009). OEA/Ser.L/V/II. Derechos de los pueblos indígenas y tribales sobre sus tierras ancestrales y recursos naturales. Normas y jurisprudencia del Sistema Interamericano de Derechos Humanos. Del 30 de diciembre.

CIDH (2009). OEA/Ser.L/V/II. Doc.54. Democracia y derechos humanos en Venezuela. Del 30 de diciembre de 2009.

CIDH (2011). Informe 64/11. Caso 12.573, Fondo, Marino López y otros (Operación Génesis). Del 31 de marzo de 2011.

CIDH (2011). OEA/Ser.L/V/II. Doc. 65. Acceso a la justicia para mujeres víctimas de violencia en las Américas. Del 28 de diciembre.

CIDH (2011). OEA/Ser.L/V/II. Doc.79. El camino hacia una democracia sustantiva: la participación política de las mujeres en las Américas.

CIDH (2014). Informe 72/14. Caso 12.665, I.V. Bolivia. OEA/Ser.L/V/ II.152. Del 15 de agosto.

CIDH (2014). OEA/Ser.L/V/II.152. Universalización del sistema interamericano de derechos humanos. Del 14 de agosto.

CIDH (2015). Informe 75/15. Caso 12.923, Fondo, Rocío San Miguel Sosay otras. Del 28 de octubre de 2015. 
Esta revista forma parte del acervo de la Biblioteca Jurídica Virtual del Instituto de Investigaciones Jurídicas de la UNAM

CIDH (2015). OAS/Ser.L/V/II.rev.2, doc. 36. Violencia contra personas LGBTI. Del 12 de noviembre. CIDH (2017). Hacia la garantía efectiva de los derechos de niñas, niños y adolescentes: Sistemas Nacionales de Protección. Del 30 de noviembre.

CIDH (2015). OAS/Ser.L/V/II.rev.2. Violencia contra Personas Lesbianas, Gay, Bisexuales, Trans e Intersex en América.

CIDH (2015). OEA/Ser.L/V/II, Doc. 47/15. Pueblos indígenas, comunidades afrodescendientes y recursos naturales: protección de derechos humanos en el contexto de actividades de extracción, explotación y desarrollo. Del 31 de diciembre.

CIDH (2015). OEA/Ser.L/V/II. Pueblos indígenas, comunidades afrodescendientes y recursos naturales: protección de derechos humanos en el contexto de actividades de extracción, explotación y desarrollo. Del 31 diciembre.

CIDH (2017). OEA/Ser.L/V/II. Doc.44/17. Las mujeres indigenas y sus derechos humanos en las Américas. Del 17 de abril.

CIDH (2018). Informe 122/18. Caso 11.656, Fondo, Marta Lucía Álvarez Giraldo. Del 5 de octubre.

CIDH (2018). OAS/Ser.L/V/II.170, Doc. 184. Avances y Desafios hacia el reconocimiento de los derechos de las personas LGBTI en las Américas. Del 7 de diciembre.

CIDH (2019). OAS/Ser.L/V/II. Situación de los derechos humanos de los pueblos indigenas y tribales de la Panamazonía. Del 29 septiembre.

CIDH (2019). OEA/Ser.L/V/II.171 Doc. 31. Compendio sobre la igualdad y no discriminación: estándares interamericanos. Del 12 de febrero de 2019.

Claude Reyes y otros vs. Chile (2006). Corte IDH. Sentencia del 29 de septiembre.

Chetus Gregor, Barie (2003). Pueblos indigenas y derechos constitucionales en América Latina: un panorama. 2a. ed., Abya Yala.

Comisión Interamericana de Mujeres (2001). Violencia en la Américas. Un análisis regional.

Comunidad Garifuna de Punta Piedra y sus miembros vs. Honduras (2015). Corte IDH. Sentencia del 8 de octubre.

Comunidad Indígena Sawhoyamaxa vs. Paraguay (2006). Corte IDH. Sentencia del 29 de marzo.

Comunidad Indígena Xákmok Kásek vs. Paraguay (2010). Corte IDH. Sentencia del 24 de agosto.

Comunidad Indigena Yakye Axa vs. Paraguay (2005). Corte IDH. Sentencia del 17 de junio. 
Esta revista forma parte del acervo de la Biblioteca Jurídica Virtual del Instituto de Investigaciones Jurídicas de la UNAM

Comunidad Mayagna (Sumo) Awas Tingni vs. Nicaragua (2001). Corte IDH. Sentencia del 31 de agosto.

Conferencia Especializada Interamericana sobre Derechos Humanos, San José, Costa Rica, 7-22 de noviembre de 1969, Actas y Documentos, pp. 125 y $159-160$

Constitución Política de los Estados Unidos Mexicanos

Convención Interamericana para la Eliminación de Todas las Formas de Discriminación contra las Personas con Discapacidad. https://wrwe. oas.org/juridico/spanish/tratados/a-65.html

Corte IDH (2018). 40 años protegiendo derechos. Corte IDH-Cooperación Alemana para el Desarrollo.

Cuscul Pivaral y otros vs. Guatemala (2018). Corte IDH. Sentencia del 23 de agosto.

Declaración Americana sobre los Derechos de los Pueblos Indígenas

Declaración de las Naciones Unidas sobre los Derechos de los Pueblos Indígenas. https://wrere.un.org/development/desa/indigenous-peoples-es/declaracion-sobre-los-derechos-de-los-pueblos-indigenas.html

Declaración Interpretativa de México. http://wrewe.oas.org/es/cidh/mandato/Basicos/convratifasp. Para una critica sobre la decisión de la Corte IDH en el caso Artavia Murillo

Delmas-Marty, Mireille (2006). Le pluralisme ordonné. Éditions du Seuil.

Duque vs. Colombia (2016). Corte IDH. Sentencia del 6 de febrero.

Escher y otros vs. Brasil (2009). Corte IDH. Sentencia del 6 de julio.

EXPEDIENTE SUP-JDC-9167/2011. Tribunal Electoral del Poder Judicial de la Federación. Juicio para la protección de los derechos políticoelectorales del ciudadano. Del 2 de noviembre.

FAÚNDEZ LEDESMA, Héctor (2004). El sistema interamericano de protección de derechos humanos, 3a. ed. Instituto Interamericano de Derechos Humanos.

Ferrajoli, Luigi (1995). Derecho y razón. Teoría del Garantismo Penal, trad. de Perfecto Andrés Ibáñez, Alfonso Ruiz Miguel, Juan Carlos Bayón Mohino, Juan Terradillos Basoco y Rocío Cantarero Bondré. Trotta.

Ferrer MAG-Gregor Poisot, Eduardo (2017). La justiciabilidad de los derechos económicos, sociales, culturales y ambientales en el sistema interamericano de derechos humanos. Comisión Nacional de Derechos Humanos.

Ferrer MaC-Gregor Poisot, Eduardo, "Le développement du corpus juris interaméricain à travers l'action prétorienne de la Cour interame-

Esta obra está bajo una Licencia Creative Commons

Atribución-NoComercial-SinDerivar 4.0 Internacional, IIJ-UNAM.

Boletin Mexicano de Derecho Comparado, núm. 160, enero-abril de 2021, pp. 191-235. 
Esta revista forma parte del acervo de la Biblioteca Jurídica Virtual del Instituto de Investigaciones Jurídicas de la UNAM

ricaine des droits de l'homme", en Varios, Les défis de l'interprétation et l'application des droits de l'homme. Del l'ouverture au dialogue, Paris, Éditions A. Pedone, 2017, pp. 197 y ss.

FiX-Zamudio, Héctor y Valencia Carmona, Salvador (2017). Derecho constitucional mexicano y comparado. 9a. ed. Porrúa.

Flor Fleire vs. Ecuador (2016). Corte IDH. Sentencia del 31 de agosto.

Fontevecchia y D'Amico vs. Argentina (2017). Corte IDH. Supervisión de cumplimiento de sentencia. Del 18 de octubre.

Forneron e hija vs. Argentina (2012). Corte IDH. Sentencia del 27 de abril.

García Ramírez, Sergio (1965). El derecho social. Revista de la Facultad de Derecho de México (59), pp. 636-639.

García Ramírez, Sergio (2003). Protección jurisdiccional internacional de los derechos económicos, sociales y culturales. Revista Cuestiones Constitucionales (9), pp. 127-157.

García RAMíREZ, Sergio (2007). Los derechos de las mujeres y la jurisdicción interamericana de derechos humanos. En Juan Soroeta Liceras (ed.). Los derechos humanos de la mujer. Cursos de Derechos Humanos de Donostia-San Sebastián. Servicio Editorial de la Universidad del País Vasco.

García Ramírez, Sergio (2012). Control judicial interno de convencionalidad. Poder Judicial del Estado de Aguascalientes.

García Ramírez, Sergio (2016a). Gobernanza, derechos humanos, migración. Revista Escriva. Revista del Colegio de Notarios del Estado de México, p. 85.

García Ramírez, Sergio (2016b). Tutela de los derechos en situaciones de excepción. Los instrumentos para la supervisión del cumplimiento de las sentencias. En Ramiro Bejarano GuzMán, Pablo Moreno GruZ y Marcela RoDRíGuez Mejía (eds). Reconciliación y derecho procesal (p. 355). Bogotá: Asociación Internacional de Derecho Procesal-Instituto Colombiano de Derecho Procesal-Universidad Externado de Colombia.

GARCía RAMíREZ, Sergio (2017). Justicia transicional y jurisprudencia interamericana. En Liliana Dimaro AgUdelo MejÍA, Giraldo DAMARIS Pabón, Luis Orlando Toro Garzón, Mónica María Bustamante RÚA y Orión VARGAS VÉLEZ (coords.). Fusticia transicional (p. 47). Medellín: Universidad de Medellín. 
Esta revista forma parte del acervo de la Biblioteca Jurídica Virtual del Instituto de Investigaciones Jurídicas de la UNAM

García RAmírez, Sergio (2018b). La Corte Interamericana a cuarenta años de su establecimiento. Revista del Posgrado en Derecho de la UNAM (9), pp. 23-72.

GARCía RAMíREz, Sergio (2018c). Panorama de la jurisprudencia interamericana sobre derechos humanos. Comisikón Nacional de Derechos Humanos.

García Ramírez, Sergio (2019). La Corte Interamericana de Derechos Humanos. 3a. ed. Porrúa.

García RAmírez, Sergio, GonZa, Alejandra y Ramos VÁzQUEz, Eréndira Nohemí (2019). La libertad de expresión en la jurisprudencia de la Corte Interamericana de Derechos Humanos. Sociedad Interamericana de PrensaInstituto Nacional de Transparencia, Acceso a la Información y Protección de Datos Personales-Tribunal Electoral del Poder Judicial de la Federación.

GARCíA ROCA, Javier (2010). El margen de apreciación nacional en la interpretación del Convenio Europeo de Derechos Humanos: soberanía e integración. CivitasThomson Reuters.

GARCÍA-SAYÁN LARRABURE, Diego (2005). Una viva interacción: Corte Interamericana y tribunales internos. En Varios autores. La Corte Interamericana de Derechos Humanos: un cuarto de siglo. 1979-2004 (pp. 325-330). San José: Corte IDH.

Garibaldi vs. Brasil (2009). Corte IDH. Sentencia del 23 de septiembre.

Garrido Baigorria vs. Argentina (1998). Corte IDH. Sentencia del 27 de agosto.

Gelman vs. Uruguay (2011). Corte IDH. Sentencia del 24 de febrero.

Gelman vs. Uruguay (2013). Corte IDH. Sentencia del 20 de marzo. Supervisión de cumplimiento de sentencia.

Gelman vs. Uruguay (2013). Corte IDH. Supervisión de cumplimiento de sentencia. Voto razonado del juez Eduardo Ferrer Mac-Gregor Poisot. Del 20 de marzo.

Godinez Cruz vs. Honduras (1989). Corte IDH. Sentencia del 20 de enero.

Gonzáles Lluy y otros vs. Ecuador (2015). Corte IDH. Sentencia del 1 de septiembre.

GonzÁlez Morales, Felipe (2013). Sistema Interamericano de Derechos Humanos. Tirant lo Blanch.

González y otras ("Campo Algodonero") vs. México (2009). Corte IDH. Sentencia del 16 de noviembre. 
Esta revista forma parte del acervo de la Biblioteca Jurídica Virtual del Instituto de Investigaciones Jurídicas de la UNAM

GozaÍni, Osvaldo Alfredo (2016). Procedimiento en la Comisión y ante la Corte Interamericana de Derechos Humanos. Ediciones Nueva Jurídica.

Granier y otros (Radio Caracas Televisión) vs. Venezuela (2015). Corte IDH. Sentencia del 22 de junio.

I. V. vs. Bolivia (2016). Corte IDH. Sentencia del 30 de noviembre.

Ivcher Bronstein vs. Perú (2001). Corte IDH. Sentencia del 6 de febrero.

Lagos del Campo vs. Perú (2017). Corte IDH. Sentencia del 31 de agosto.

López Lone y otros vs. Honduras (2015). Corte IDH. Sentencia del 5 de octubre.

López Soto y otros vs. Venezuela (2018). Corte IDH. Sentencia del 26 de septiembre.

MACKAY, Fergus (1999). Los derechos de los pueblos indigenas en el sistema internacional. Asociación Pro Derechos Humanos-Federación Internacional de Derechos Humanos.

MARTIN, Claudia (2017). La mobilisation des sources extérieures par la Cour Interaméricaine des droits de l'homme. L'exemple du droit à la vie. En Varios autores. Les défis de l'interprétation et l'application des droits de l'homme. Del l'ouverture au dialogue (pp. 243 y ss.). Paris: Éditions A. Pedone.

Masacre Plan de Sánchez vs. Guatemala (2004). Corte IDH. Reparaciones. Del 19 de noviembre. Comunidad Moiwana vs. Surinam (2005). Corte IDH. Sentencia del 15 de junio.

Masacres de Río Negro vs. Guatemala (2012). Corte IDH. Sentencia del 4 de septiembre.

Mejía Guerrero, Luz Patricia (2012). La Comisión Interamericana de Mujeres y la Convención de Belém do Pará. Impacto en el Sistema Interamericano de Derechos Humanos. Revista IIDH (56), pp. 196-197. Mémoli vs. Argentina (2013). Corte IDH. Sentencia del 22 de agosto. Muelle Flores vs. Perú (2019). Corte IDH. Sentencia del 6 de marzo.

Mujeres Victimas de Tortura Sexual en Atenco (2018). Corte IDH. Sentencia del 28 de noviembre. Fernández Ortega vs. México (2010). Corte IDH. Sentencia del 30 de agosto.

Niñas Yean y Bosico vs. República Dominicana (2005). Corte IDH. Sentencia del 8 de septiembre.

OC-4/84 (1984). Corte IDH. Propuesta de modificación a la Constitución Política de Costa Rica relacionada con la naturalización. Del 19 de enero. 
Esta revista forma parte del acervo de la Biblioteca Jurídica Virtual del Instituto de Investigaciones Jurídicas de la UNAM

OC-5/85 (1985). Corte IDH. Del 13 de noviembre.

Opinión Consultiva OC-18/03. Corte IDH. Condición jurídica y derechos de los migrantes indocumentados. Del 17 de septiembre de 2003. Opinión Consultiva OC-24/17. Corte IDH. Identidad de género, e igualdad y no discriminación a parejas del mismo sexo. Del 24 de noviembre de 2017.

Opinión Consultiva OG-6/86 (1986). Corte IDH. Del 9 de mayo.

Opinión Consultiva OC-8/87. Corte IDH. Del 30 de enero de 1987.

Ortiz Ahlf, Loretta (2005). Armonización legislativa interna de las normas internacionales en materia de derechos humanos. En Varios autores. La armonización de los tratados internacionales de derechos humanos en México (pp. 293-302). México: Secretaria de Relaciones Exteriores-Programa de Cooperación sobre Derechos Humanos México-Comisión Europea.

Palma Mendoza y otros vs. Ecuador (2012). Corte IDH. Sentencia del 3 de septiembre.

Penal Miguel Castro Castro vs. Perú (2006). Corte IDH. Sentencia del 25 de noviembre.

Perozo y otros vs. Venezuela (2009). Corte IDH. Sentencia del 28 de enero.

Poblete Vilches y otros vs. Chile (2018). Corte IDH. Sentencia del 8 de marzo.

Protocolo adicional a la Convención Americana sobre Derechos $\mathrm{Hu}-$ manos en materia de Derechos Económicos, Sociales y Culturales (Protocolo de San Salvador), del 17 de noviembre de 1988.

Pueblo Indígena Kichwa de Sarayaku vs. Ecuador (2012). Corte IDH. Sentencia del 27 de junio. Pueblos Indígenas Kuna de Madungandí y Emberá de Bayano y sus Miembros vs. Panamá (2014). Corte IDH. Sentencia del 14 de octubre.

Pueblo Indígena Xucuru y sus miembros vs. Brasil (2018). Corte IDH. Sentencia del 5 de febrero.

Pueblo Saramaka vs. Surinam (2007). Corte IDH. Sentencia del 28 de noviembre.

Pueblo Saramaka vs. Surinam (2007). Corte IDH. Sentencia del 28 de noviembre.

Pueblos Kaliña y Lokono vs. Surinam (2015). Corte IDH. Sentencia del 25 de noviembre.

Pueblos Kaliña y Lokono vs. Surinam (2015). Corte IDH. Sentencia del 25 de noviembre.

Quintana Osuna, Karla I. (2017). Algunas reflexiones sobre la evolución en el reconocimiento de los derechos de los pueblos indígenas y tri-

Esta obra está bajo una Licencia Creative Commons

Atribución-NoComercial-SinDerivar 4.0 Internacional, IIJ-UNAM.

Boletin Mexicano de Derecho Comparado, núm. 160, enero-abril de 2021, pp. 191-235. 
Esta revista forma parte del acervo de la Biblioteca Jurídica Virtual del Instituto de Investigaciones Jurídicas de la UNAM

bales en el Sistema Interamericano. En Karla I. QUinTana OsUnA y Rogelio FLORES (coords.). Los derechos de los pueblos indígenas. Una visión desde el sistema interamericano de protección de los derechos humanos (pp. 16-24). México: Instituto de Estudios Constitucionales del Estado de Querétaro, Colección Constitución y Derechos.

Ramirez Escobar y otros vs. Guatemala (2018). Corte IDH. Sentencia del 9 de marzo.

Reglas de Brasilia sobre Acceso a la Justicia de las Personas en Condición de Vulnerabilidad (2008). XIV Cumbre Judicial Iberoamericana. https://wrere.acnur.org/fileadmin/Documentos/BDL/2009/7037.pdf

Ricardo Canese vs. Paraguay (2004). Corte IDH. Sentencia del 31 de agosto. Rodríguez Recia, Víctor (2018). Constitución Política de los Estados Unidos Mexicanos. Instituto Interamericano de Responsabilidad Social y Derechos Humanos.

Rosendo Cantú y otra vs. México (2010). Corte IDH. Sentencia del 31 de agosto.

ROUSSET SIRI, Andrés (2018). Ejecución de sentencias de la Corte Interamericana de Derechos Humanos. Ediar.

Ruiz ChIRIBOGA, Oswaldo y Donoso, Gina (2019). Jurisprudencia de la Corte IDH sobre los Pueblos Indígenas y Tribales Fondo y Reparaciones. En Christian STEInER y Marie-Christine FuCHS (eds.). Convención Americana sobre Derechos Humanos. Comentario (pp. 1131 y ss.). 2a. ed. Bogotá: Konrad Adenauer Stiftung.

SAGÜES, Néstor P. (2016). La interpretación de los derechos humanos en las jurisdicciones nacional e internacional. En José F. PALOMINO Manchego y José Carlos Remotti Carbonell (coords.). Derechos humanos y Constitución en Iberoamérica (pp. 48 y ss.). Lima: Instituto Iberoamericano de Derecho Constitucional-Ilustre Colegio de Abogados de Lima-Iustitia-Universidad Inca Garcilaso de la Vega.

San Miguel Sosa y otras vs. Venezuela (2018). Corte IDH. Sentencia del 8 de febrero de 2018.

Santiago, Alfonso y Bellocahio, Lucía (dirs.) (2018). Historia de la Corte Interamericana de Derechos Humanos. La Ley.

SANTOscoy, Bertha (1995). La Commission Interaméricaine des Droits del Homme. Publications de l'Institut Universitaire de Hautes Etudes Internationales. 
Esta revista forma parte del acervo de la Biblioteca Jurídica Virtual del Instituto de Investigaciones Jurídicas de la UNAM

SGJN, Pleno, Contradicción de Tesis 293/2011, 3 de septiembre de 2013, p. 41.

Sierra Porto, Humberto A. (2016). Los retos jurídicos del proceso de paz colombiano. En Ramiro Bejarano Gúzman, Pablo Moreno Cruz y Marcela Rodríguez Mejía (eds.). Reconciliación y derecho procesal (82 y ss.). Bogotá: Asociación Internacional de Derecho Procesal-Instituto0 Colombiano de Derecho Procesal-Universidad Externado de Colombia.

Silva García, Fernando y Silva Meza, Juan N. (2009). Derechos fundamentales. Porrúa.

StaVEnHAGEN, Rodolfo (2007). Los pueblos indígenasy sus derechos. UNESCO. Suárez Peralta vs. Ecuador (2013). Corte IDH. Sentencia del 21 de mayo.

Tarazona Arrieta y otros vs. Perú (2014). Corte IDH. Sentencia del 15 de octubre.

Tiu Tojín vs. Guatemala (2008). Corte IDH. Sentencia del 26 de noviembre. Trabajadores Cesados de Petroperú y otros vs. Perú (2017). Corte IDH. Sentencia del 23 de noviembre.

Trabajadores Cesados del Congreso (Aguado Alfaro y otros) vs. Perú (2006). Corte IDH. Sentencia del 24 de noviembre.

Tristán Donoso vs. Panamá (2009). Corte IDH. Sentencia del 27 de enero.

ÚBEDA de Torres, Amaya (2007). Democracia y derechos humanos en Europa y en América. Estudio comparado de los sistemas europeo e interamericano de protección de los derechos humanos. Reus.

ÚbedA DE TORReS, Amaya (2007). Democracia y derechos humanos en Europa y América. Reus.

Unión Panamericana (1960). Quinta Reunión de Consulta de Ministros de Relaciones Exteriores. Acta Final. Resolución VIII Derechos Humanos.

Unión Panamericana. Conferencias Internacionales Americanas Segundo suplemento 1945-1954. Unión Panamericana (1956). Conferencia Interamericana sobre Problemas de la Guerra y la Paz. Acta Final, "Reorganización, Consolidación y Fortalecimiento del Sistema Interamericano".

UPRIMMY YePes, Rodrigo y SÁNCHez DuQUE, Luz María (2019). Artículo 24. Igualdad ante la ley. en Varios autores. Convención Americana sobre Derechos Humanos. Comentario, Christian SteIneR y Marie-Christine FuchS (eds.), 2a. ed. Konrad Adenauer Stiftung, 2019, pp. 708 y ss.

Valle Faramillo y otros vs. Colombia (2008). Corte IDH. Sentencia del 27 de noviembre.

Esta obra está bajo una Licencia Creative Commons

Atribución-NoComercial-SinDerivar 4.0 Internacional, IIJ-UNAM.

Boletin Mexicano de Derecho Comparado, núm. 160, enero-abril de 2021, pp. 191-235. 
Esta revista forma parte del acervo de la Biblioteca Jurídica Virtual del Instituto de Investigaciones Jurídicas de la UNAM

Varios autores (2005). La Corte Interamericana de Derechos Humanos. Un cuarto de siglo: 1979-2004. Corte IDH.

Varios autores (2016). Temas y tendencias del constitucionalismo moderno. Universidad Nacional Autónoma de México, Instituto de Investigaciones Jurídicas.

VÁzQUEz Gómez-Bisogno, Francisco (2018). El control de convencionalidad. Hacia una teoría de la argumentación convencional. Tirant lo Blanch.

Velásquez Paiz y otros vs. Guatemala (2015). Corte IDH. Sentencia del 19 de noviembre.

Velásquez Rodríguez vs. Honduras (1988). Corte IDH. Sentencia del 29 de julio. Vera Vera y otra us. Ecuador (2011). Corte IDH. Sentencia del 19 de mayo.

VICENTE, Esther (2010). La Comisión y Corte Interamericanas ante los derechos de las mujeres. En Juan A. CRUz PARCERO y Rodolfo VÁZQUEZ (coords.). Derechos de las mujeres en el derecho internacional (pp. 149 y ss.). Fontamara-Suprema Corte de Justicia de la Nación.

Villaroel Villaroel, Darío (2004). Derecho de los tratados en las constituciones de América. Porrúa.

Vivanco, José Miguel (2005). Experiencias positivas y obstáculos para armonizar la legislación de derechos humanos en América Latina. En Varios autores. La armonización de los tratados internacionales de derechos humanos en México (pp. 27-36). México: Secretaria de Relaciones Exteriores-Programa de Cooperación sobre Derechos Humanos MéxicoComisión Europea.

XVII Cumbre Judicial Iberoamericana (2014). http://wrere.cumbrejudicial. org/productos-y-resultados/productos-axiologicos/item/38-protocolo-de-acceso-ala-justicia-para-personas-y-grupos-vulnerables

Yatama os. Nicaragua (2005). Corte IDH. Sentencia del 23 de junio de 2005. 